\author{
Amalia Maceda Rubio \\ Departamento de Geografía. Universidad de Oviedo
}

\title{
El vino y el sistema de protección de su origen y calidad
}

\section{RESUMEN}

En este artículo se analizan los eslabones de la cadena vitivinícola correspondientes a las fases agraria e industrial y se consideran más específicamente los vinos que cuentan con menciones de calidad diferenciada. La evolución y distribución del viñedo y las características de las explotaciones vitícolas, la producción de vino y la importancia creciente de los vinos con denominación de origen y otros tipos de distinción, así como la industria vinícola y las características y tipos de empresas en el sector bodeguero, constituyen los contenidos fundamentales del estudio.

\section{RÉSUMÉ}

Le vin et le système de protection de son origine et sa qualité-. En cet article on vise à analyser les liens de la chaîne de production du vin correspondant aux phases agraire et industrielle. On prend en compte plus spécifiquement les vins qui ont été labélisés avec des mentions de qualité. L'évolution et la distribution des vignobles, les caractéristiques des domaines, la production du vin et l'importance croissante des vins

\section{EL VIÑEDO, LA UVA Y EL VINO EN ESPAÑA}

\section{El VIÑEDO: SUPERFICIE, EVOLUCIÓN Y DISTRIBUCIÓN DE} LAS PLANTACIONES

$E$ n las últimas décadas España perdió una parte importante de su superficie vitícola, pasando del miloón y medio de hectáreas en los primeros años ochenta a menos de un millón en el periodo posterior a 2010, con una disminución de unas 20.000 hectáreas/año, aunque apreciándose una leve recuperación en las fechas más re-
d'Appellation d'Origine Contrôlée (AOC) - et d'autres certificationsainsi que l'industrie du vin et les caractéristiques et types d'entreprises de la filière vin font l'objet de cette étude.

\section{Abstract}

The wine and its origin and quality protection system-. This article aims to analyse the links of wine production corresponding to agrarian and industrial phases. Wines with quality certifications are specifically considered. The evolution and distribution of vineyard, the wine production and growing importance of wines with designation of origin (and other types of distinctions), as well as wine industry, types and characteristics of companies in this sector constitute the contents of this study.

\section{Palabras Clave/Mots Clé/Keywords}

Viñedo, vino, calidad, denominación de origen, industria vinícola, bodegas.

Vignoble, vin, qualité, appellation d'origine, industrie du vin, domaines Vineyard, wine, quality, designation of origin, wine industry, wineries cientes. Pese a ello, mantiene el viñedo más extenso del mundo y posee el $30 \%$ del existente en la Unión Europea (Fig. 1). Disputa con Francia e Italia las primeras posiciones en la producción de vino y es líder en el volumen de la exportación mundial, si bien su posición se rezaga en facturación por el menor precio de nuestros vinos, 1,16 euros de media por litro frente a 2,50 euros de los vinos italianos y 5,30 de los franceses (Icex, 2014).

Según datos recientes del Ministerio de Agricultura, Alimentación y Medio Ambiente (2014a), el viñedo ocupaba en 2013947.000 hectáreas, la inmensa mayoría de 


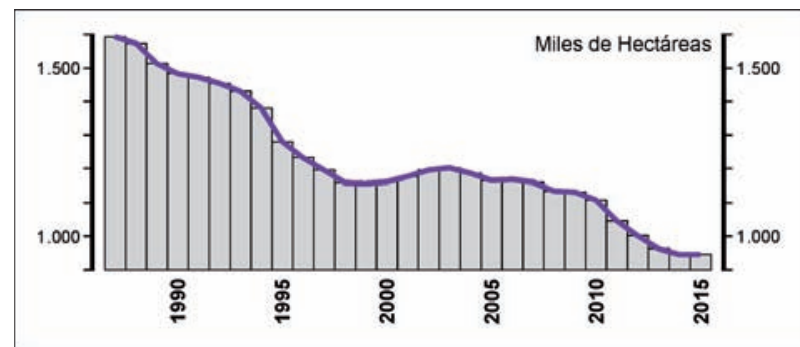

FIG. 1. Evolución de la superficie de viñedo, 1985-2015. Fuente: elaborado a partir de la información de Ministerio de Agricultura, Alimentación y Medio Ambiente: Anuarios Estadísticos y Encuesta de Superficies de Cultivo.

las cuales correspondían a la uva de vinificación; el de pasificación se limitaba a 1.700 ha, todas en Andalucía, y el de uva de mesa no alcanzaba las 14.000, con la Comunidad Valenciana y Murcia como principales productoras. Ciudad Real contaba con la mayor extensión, 157.000 hectáreas, y junto con las demás provincias manchegas, concentraba el $47 \%$ del total nacional. Otras provincias contaban también con superficies considerables, aunque sin llegar a las magnitudes de La Mancha; las diez primeras acaparaban tres cuartas partes del viñedo (Fig. 2) y el cuarto final se repartía de forma más fragmentada por el resto del país.

La merma de la superficie vinícola, antes mencionada, afectó a la mayor parte de las regiones. En lo que va de siglo xxi sólo Cantabria, Baleares, País Vasco, Galicia y La Rioja presentan un saldo positivo, con alguna ganancia superficial. Las disminuciones tuvieron un carácter más generalizado, correspondiendo las más cuantiosas a la Comunidad Valenciana, Aragón, Madrid, Navarra y Murcia, que perdieron el $20 \%$ de la superficie plantada, y a Asturias, que redujo a la mitad su ya mermado viñedo. En paralelo ha ido creciendo la importancia del regadío. Treinta años atrás se regaban unas 50.000 ha $(4 \%$ de la superficie plantada); en 2000 unas 134.000 (11\%); y en 2013 superaban las 215.000 ha $(23 \%)^{1}$. De esta última extensión más de la mitad se encontraba en La Mancha, aunque en términos relativos la superficie regada era más relevante en Navarra (57\%), Baleares (52\%), Murcia (41\%) y Comunidad Valenciana (31\%).

Según el Ministerio de Agricultura en su informe sobre Potencial de producción vitícola en la Unión Euro-

\footnotetext{
1 La fuente es el Anuario de Estadística Agraria, del Ministerio de Agricultura. Otras informaciones procedentes del mismo organismo, como la Encuesta sobre Superficies y Rendimientos, elevan las hectáreas regadas a 341.865 en el mismo año 2013 y a 365.767 en 2015 , representando el $37 \%$ de la superficie total de viñedo.
}

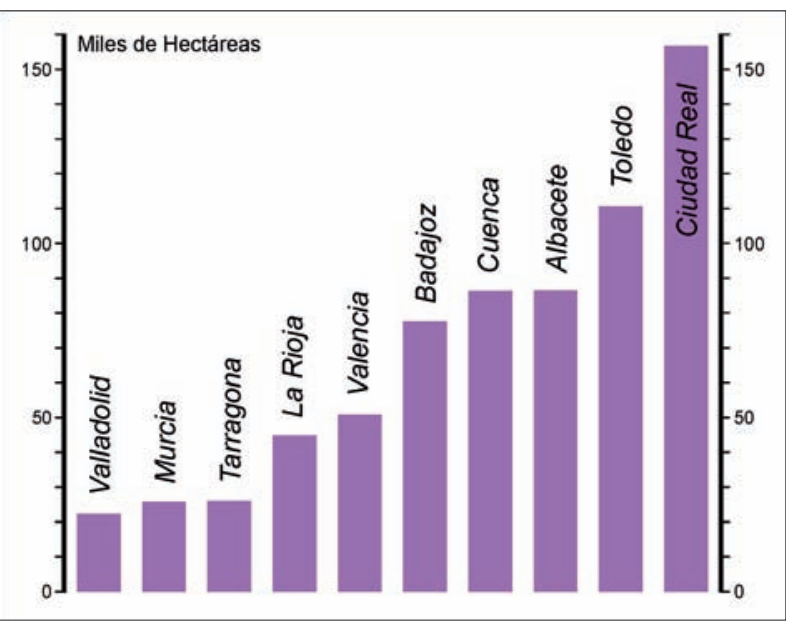

FIG. 2. Las diez provincias con mayores superficies de viñedo. Fuente: elaborado a partir de la información de Ministerio de Agricultura, Alimentación y Medio Ambiente: Anuario Estadístico, 2014.

pea y en España, inventario de potencial vitícola a 31 de julio de 2014, el conjunto de la superficie vinícola se repartía en más de medio millón de explotaciones. El INE, por su parte, en su Censo Agrario de 2009, las rebajaba a 136.000 (el $14 \%$ de las 971.000 censadas); y la base de datos de Eurostat a 391.537 (el 16,5\% de las de la UE-27), las mismas que recoge el Ministerio de Agricultura en la Encuesta Base de Viñedo 2009. Las mayores disparidades entre las distintas fuentes corresponden a Galicia (Cuadro I).

Según el organismo estadístico europeo, una característica relevante del cultivo vitícola es su alta fragmentación. Aproximadamente, dos tercios de las explotaciones cuentan con menos de una hectárea de viñedo y la mitad no alcanza la media hectárea, afectando el mayor fraccionamiento a las regiones septentrionales (Galicia, Asturias, Cantabria, Castilla y León) y a las islas. En Castilla-La Mancha, Extremadura, Cataluña y Murcia, sin embargo, las explotaciones con más de cinco ha de viñedo sobrepasan el $25 \%$ o se acercan a esa proporción (Fig. 3).

La misma fuente da cuenta de la escasa especialización vitícola de las explotaciones en la mayor parte de las regiones, pues, con las excepciones de País Vasco, La Rioja, Cataluña y Murcia, donde las explotaciones vitícolas dedican más del $50 \%$ de la superficie agrícola utilizada a la producción de uvas (aproximándose Castilla-La Mancha a esa proporción), el viñedo es un uso agrícola secundario, al que se dedican partes minoritarias del terreno disponible (Fig. 4).

La segmentación del viñedo se refuerza si consideramos la división parcelaria. Sin contar las de Navarra y el 
Cuadro I. Viñedo y vino por comunidades autónomas

\begin{tabular}{|c|c|c|c|c|c|c|c|c|c|c|c|c|c|}
\hline & \multicolumn{6}{|c|}{ Superficie, hectáreas } & \multicolumn{2}{|c|}{ Explotaciones } & \multicolumn{5}{|c|}{ Producción de vino, hectolitros } \\
\hline & \multicolumn{3}{|c|}{$2013(1)$} & \multicolumn{3}{|c|}{2015 (2) } & \multirow{2}{*}{$\begin{array}{c}\text { M. }^{\circ} \\
\text { Agricult. } \\
(3) \\
\end{array}$} & \multirow[b]{2}{*}{$\begin{array}{c}\text { Eurostat } \\
(4) \\
\end{array}$} & \multicolumn{3}{|c|}{ Campaña 2013/2014 (5) } & \multirow{2}{*}{$\begin{array}{c}\text { Campaña } \\
2014 / 2015 \\
(6) \\
\\
\text { Total } \\
\end{array}$} & \multirow{2}{*}{$\begin{array}{c}\text { Campaña } \\
\text { 2015/2016 } \\
(7) \\
\\
\text { Total }\end{array}$} \\
\hline & Secano & Regadío & Total & Secano & Regadío & Total & & & Blancos & $\begin{array}{c}\text { Tintos } \\
\text { y rosados }\end{array}$ & Total & & \\
\hline Andalucía & 28.139 & 2.137 & 30.276 & 22.663 & 4.202 & 26.865 & 19.716 & 15.781 & 1.239 .318 & 174.080 & 1.413 .398 & 1.082 .520 & 1.133 .236 \\
\hline Aragón & 28.103 & 9.866 & 37.969 & 25.378 & 11.372 & 36.750 & 15.985 & 17.735 & 155.320 & 871.330 & 1.026 .650 & 1.102 .155 & 1.435 .534 \\
\hline Asturias & 70 & - & 70 & 1 & & 1 & 698 & 267 & 394 & 906 & 1.300 & 1.911 & 1.671 \\
\hline Baleares & 886 & 942 & 1.828 & 1.313 & 1.568 & 2.881 & 1.261 & 1.026 & 13.029 & 32.878 & 45.907 & 44.440 & 57.624 \\
\hline Canarias & 6.658 & 2.052 & 8.710 & 5.354 & 3.051 & 8.405 & 42.737 & 15.179 & 59.410 & 75.867 & 135.277 & 95.963 & 102.717 \\
\hline Cantabria & 142 & - & 142 & 14 & & 14 & 296 & 161 & 395 & 27 & 422 & 993 & - \\
\hline C.-La Mancha & 315.357 & 126.649 & 442.006 & 252.838 & 220.431 & 473.268 & 85.672 & 100.004 & 14.548 .261 & 11.266 .930 & 25.815 .191 & 20.045 .164 & 18.303 .973 \\
\hline C. y León & 71.254 & 2.848 & 74.102 & 43.522 & 19.836 & 63.359 & 85.825 & 62.279 & 832.108 & 1.269 .375 & 2.101 .483 & 2.254 .090 & 1.835 .818 \\
\hline Cataluña & 51.316 & 3.586 & 54.902 & 46.016 & 8.559 & 54.576 & 12.413 & 11.191 & 2.715 .469 & 987.279 & 3.702 .748 & 3.278 .648 & 3.302 .038 \\
\hline Extremadura & 74.829 & 6.843 & 81.672 & 58.672 & 21.720 & 80.391 & 16.081 & 14.039 & 2.249 .710 & 1.703 .305 & 3.953 .015 & 4.015 .136 & 3.827 .327 \\
\hline Galicia & 24.904 & - & 24.904 & 25.304 & 693 & 25.997 & 220.815 & 83.942 & 374.142 & 70.471 & 444.613 & 367.099 & 454.782 \\
\hline Madrid & 10.458 & 704 & 11.162 & 9.493 & 1.211 & 10.704 & 8.921 & 9.301 & 80.072 & 97.552 & 177.624 & 133.505 & 122.384 \\
\hline Murcia & 18.235 & 12.681 & 30.916 & 19.770 & 10.905 & 30.675 & 3.883 & 6.376 & 23.677 & 863.098 & 886.775 & 581.208 & 663.368 \\
\hline Navarra & 8.313 & 10.823 & 19.136 & 7.475 & 11.950 & 19.425 & 4.029 & 5.658 & 58.800 & 625.085 & 683.885 & 725.773 & 848.916 \\
\hline País Vasco & 13.046 & 1.250 & 14.296 & 11.858 & 1.655 & 13.513 & 2.256 & 4.249 & 60.584 & 571.558 & 632.142 & 823.999 & 778.7978 \\
\hline La Rioja & 31.808 & 12.933 & 44.741 & 25.604 & 26.464 & 52.068 & 12.668 & 13.345 & 114.981 & 1.773 .846 & 1.888 .827 & 2.119 .914 & 2.245 .992 \\
\hline C. Valenciana & 48.378 & 21.760 & 70.138 & 46.692 & 22.150 & 68.842 & 21.188 & 31.004 & 492.786 & 2.064 .543 & 2.557 .329 & 1.538 .048 & 2.104 .999 \\
\hline TotAL & 731.896 & 215.074 & 946.970 & 601.966 & 365.767 & 967.733 & 554.444 & 391.537 & 23.343 .372 & 22.735 .173 & 46.078 .545 & 38.210 .566 & 44.228 .357 \\
\hline
\end{tabular}

País Vasco, las parcelas de viñedo se acercan a 1.800.000, el $3,4 \%$ de las catastradas ${ }^{2}$, y concentran el $2,3 \%$ de la superficie rústica, lo que revela su menor tamaño medio $(0,62 \mathrm{ha})$ respecto al del total de las parcelas, considerados todos los usos $(0,91 \mathrm{ha})$. Además, donde menores son las explotaciones más intensa es la parcelación: en Galicia, Asturias, Cantabria, Castilla y León, Baleares y Canarias, además de La Rioja, cuentan con el tamaño

\footnotetext{
${ }^{2}$ Estadísticas del Catastro, 2005. Sin los territorios forales, la información catastral abarca 7.585 municipios, de los que 4.028 cuentan con alguna superficie de viñedo, aunque en muchos de ellos se trata de extensiones muy reducidas, hasta el punto de que si considerásemos sólo los que cuentan con más de 10 ha, la cifra descendería a 2.600 y a 1.535 examinando los que tienen más de 50 ha. Las 10.000 hectáreas de viñedo se sobrepasan en diez municipios, siete manchegos (Villarrobledo, Socuéllamos, Valdepeñas, Alcázar de San Juan, Campo de Criptana, Corral de Almaguer y Tomelloso) más Yecla, Jumilla y Requena. En los dos últimos son más de 20.000 las hectáreas de viñedo.
}

medio de parcela de viñedo inferior a la del conjunto del «territorio común». Murcia, Extremadura y Castilla-La Mancha sobrepasan la hectárea y Cataluña se acerca a ese valor superficial.

En lo que sobresale el viñedo, en comparación con los demás parámetros, es en el valor catastral que representa, superior a su participación en parcelas y en superficies, destacando particularmente tal indicador en Castilla-La Mancha y La Rioja y, también, aunque en un nivel inferior, en Murcia y en la Comunidad Valenciana (Cuadro II).

\section{LA UVA Y EL VINO}

La producción de uva osciló en los últimos años entre los 5,5 y 7,5 millones de toneladas, dedicándose 


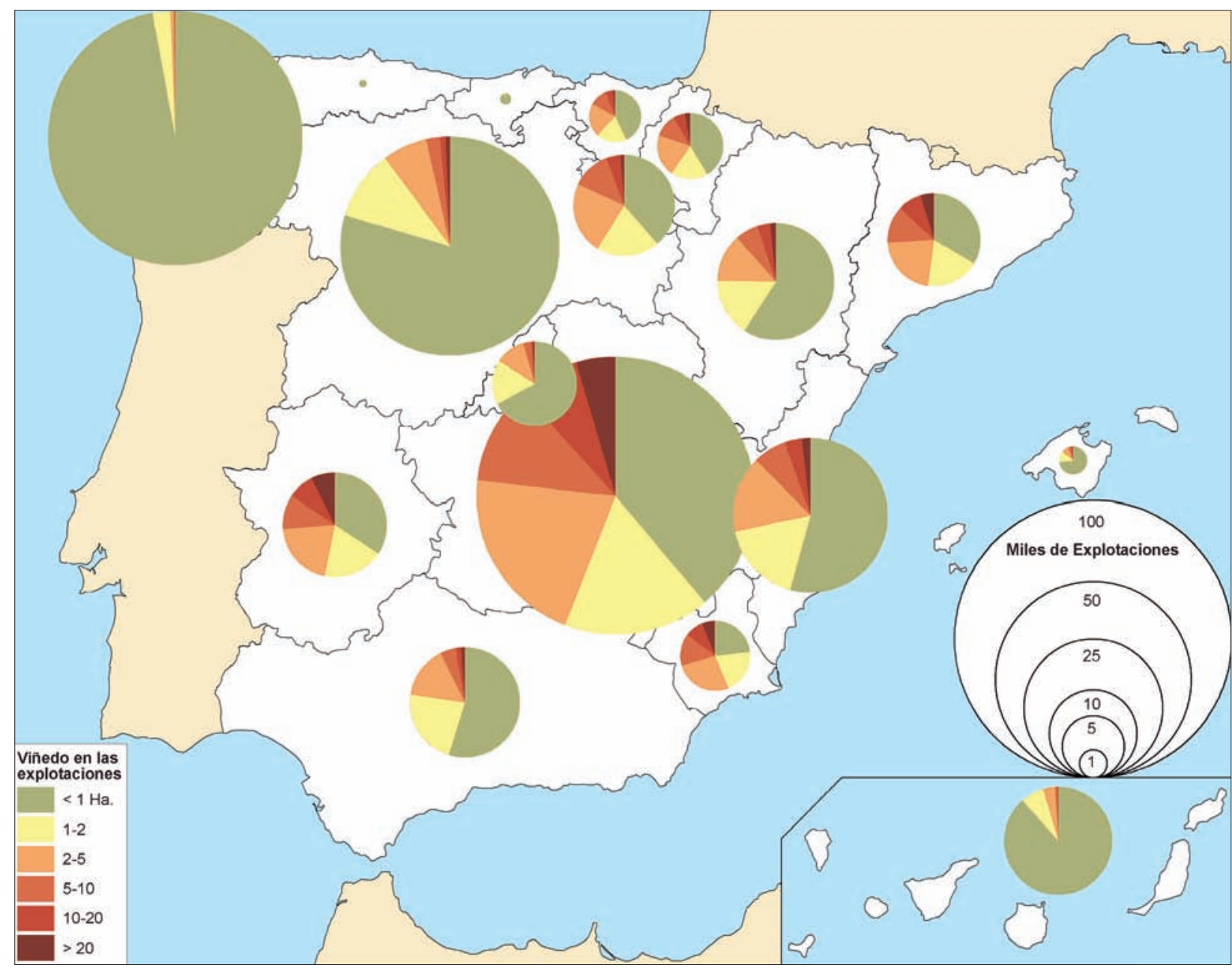

FIG. 3. Distribución de las explotaciones vitícolas según la superficie de viñedo de que disponen. Fuente: elaborado a partir de datos de Eurostat.

la inmensa mayoría a la vinificación. La productividad media del viñedo destinado a obtener vino y mosto fue en 2013 de $6.959 \mathrm{~kg} / \mathrm{ha}$ en secano y 13.493 en regadío (Ministerio de Agricultura, 2014a). Ahora bien, existían importantes diferencias regionales. En secano, Cádiz, Córdoba, Barcelona y Ciudad Real superaban los $10.000 \mathrm{~kg} / \mathrm{ha}$; Teruel, Ávila, Salamanca, Castellón y las dos provincias canarias no alcanzaban los 2.000. Y en regadío La Mancha obtenía de media $17.000 \mathrm{~kg} / \mathrm{ha}$, en buena medida gracias a los excepcionales rendimientos que se alcanzaron en la provincia de Ciudad Real $(22.000 \mathrm{~kg} / \mathrm{ha})$.

La productividad del viñedo de vinificación se ha incrementado notablemente en los últimos años. En 2000 era de $5.082 \mathrm{~kg} / \mathrm{ha}$ en secano y de 11.177 en regadío, 2.000 menos de las cuantías señaladas antes para ambos sistemas. Entre las causas de esta mejora se encontraría la extensión del riego que, según algunas fuentes del Ministerio de Agricultura, alcanzaría al $37 \%$ de la superficie vitícola total (véase nota 1). También la migración de las cepas desde suelos pobres hacia otros más ricos; el uso creciente de plantas e injertos certificados; la tendencia a aumentar la densidad de plantación, hacia unas 2.500 a 3.500 cepas/ha (relacionada con el uso más frecuente de conducciones en espaldera), etc. Sin embargo, no cabe esperar grandes mejoras en la productividad futura dada la limitación de rendimientos en los vinos de calidad, en torno a $6.000-7.000 \mathrm{~kg} / \mathrm{ha}$ para la producción de uva tinta y $9.000 / 10.000 \mathrm{~kg} / \mathrm{ha}$ para la producción de uva blanca (Lissarrague y Martínez de Toda, 2009).

En 2013 la producción de vino ascendió a 46 millones de hectolitros. Con el mosto, los productos derivados de la transformación de la uva sumaron 52,5 millones de hectolitros (Fig. 5). 
Cuadro II. El viñedo: indicadores catastrales

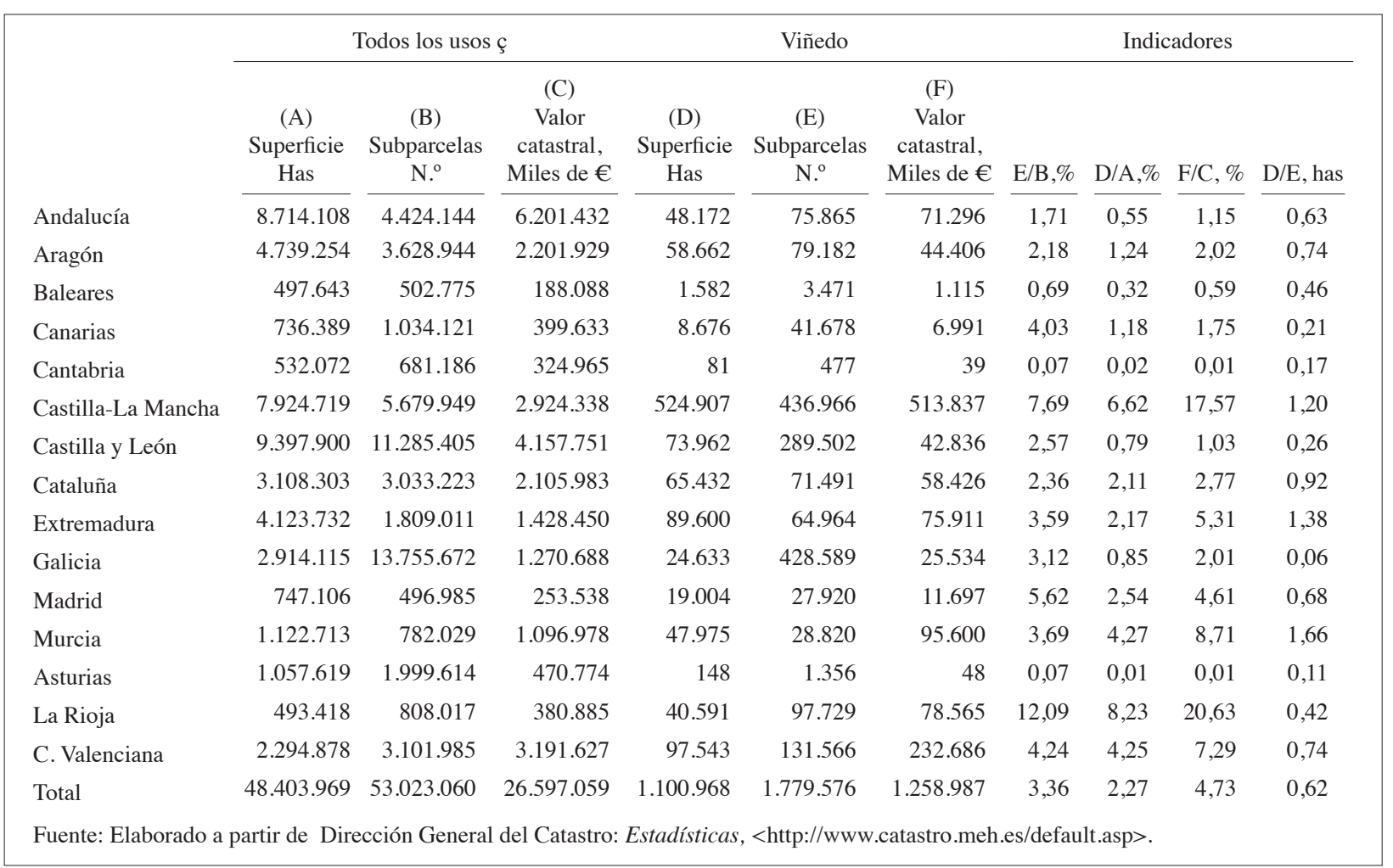

Hace algunos años la producción de blancos superaba en la mayor parte de las campañas a la de tintos y rosados. Entrados en los años 2000 ocurre más frecuentemente lo contrario. Unos y otros proceden de una amplia variedad de uvas, algunas de las cuales están muy difundidas espacialmente, mientras que otras tienen una presencia más local y delimitada. En este último caso dan carácter y singularidad a los vinos producidos en los territorios vitivinícolas en los que se asientan.

Entre las uvas blancas, la más utilizada es la variedad airen, extendida sobre más de 200.000 ha, la mitad de las de su tipo, localizándose mayoritariamente en Castilla-La Mancha. Le sigue con 40.000 ha la macabeo (autorizada para la fabricación de cava), cuya presencia en doce regiones vinícolas la convierte en la más difundida, siendo también la de mayor presencia en Cataluña, Aragón, País Vasco y La Rioja; y en tercer lugar la pardina, con 27.000 ha, plantadas en su práctica totalidad en Extremadura, donde viene a suponer la mitad de la uva blanca. Del resto, ninguna alcanza las 20.000 ha, pese a lo cual alguna de ellas ha llegado a caracterizar ciertas denominaciones de origen o regiones vinícolas: Albariño en Rías Baixas; Hondarribi Zuri, en el txacolí del País
Vasco; Listan Blanco, en Canarias; Verdejo, en Rueda; o Pedro Ximénez, Palomino y Moscatel en el marco de la denominación de Jerez.

Entre las uvas tintas también hay una que predomina superficialmente, la tempranillo, con más de 200.000 ha y una representación entre las de su tipo similar a la que alcanza la airen en el suyo, con presencia en los viñedo de todas las regiones y ocupando la primera posición en los de Andalucía, Canarias, Castilla-La Mancha, Castilla y León, Extremadura, Navarra, País Vasco y La Rioja. Le siguen, con más de 60.000 ha cada una, las variedades bobal y garnacha tinta, repartida la primera por Castilla-La Mancha y la Comunidad Valenciana, y ocupando la segunda el primer lugar en Aragón, Cataluña y Madrid. La monastrell, con 45.000 hectáreas, es una de las más utilizadas por los vinos de Levante y ocupa un lugar especialmente destacado en Murcia Y aún hay otras tres variedades con más de 20.000 ha plantadas: cavernet sauvignon, garnacha tintorera, la más frecuente en Galicia, y syrah, que, como la mayor parte del resto, aparece particularmente bien representada en el extenso viñedo manchego (Ministerio de Agricultura, 2015b). 


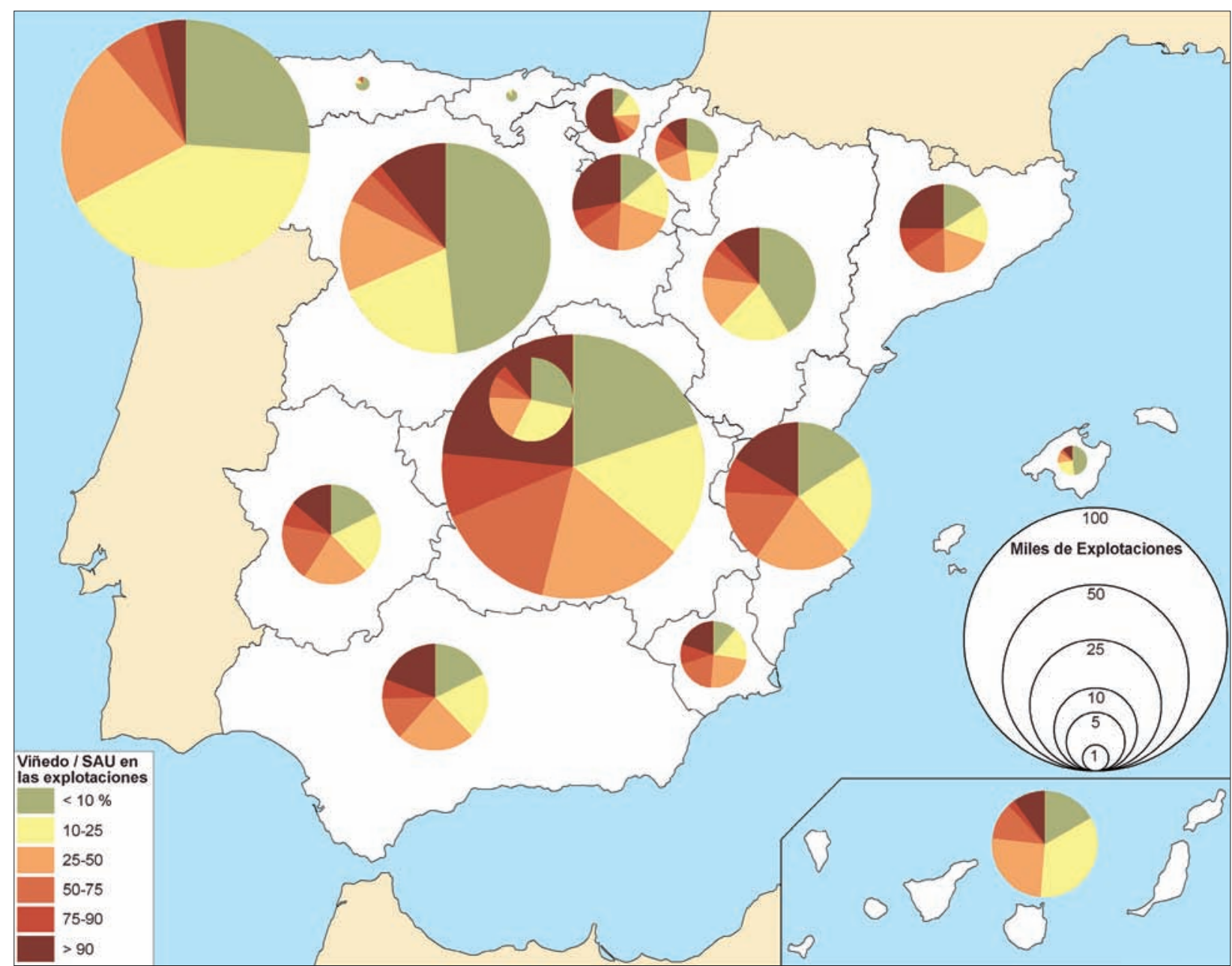

FIG. 4. Distribución de las explotaciones vitícolas según la proporción del viñedo sobre la superficie agrícola utilizada. Fuente: elaborado a partir de datos de Eurostat.

Los cincuenta espacios provinciales contribuyeron a aquella producción vinícola, aunque con aportaciones muy desiguales. Ciudad Real aportó 11,5 millones de hectolitros y otros siete (Toledo, Badajoz Barcelona, Valencia, La Rioja, Tarragona y Valladolid) más de un millón cada uno; en conjunto, de esas ocho provincias se obtuvo el $83 \%$ del volumen total. La menor producción correspondió a Cantabria (422 hl) (Fig. 6).

En términos económicos el vino y el mosto constituyen la principal partida del valor de la rama agraria en la comunidad castellano-manchega y ocupan el tercer lugar en La Rioja, quedando relegados a posiciones inferiores en las otras regiones. En el conjunto de España contribuye en un 3,28\% al citado valor de la rama agraria y en un $5,7 \%$ al valor de la producción vegetal (Ministerio de Agricultura 2012).

\section{VINO CON CALIDAD DIFERENCIADA}

Dentro de la producción vinícola ha ido ganando importancia la que corresponde a los vinos que cuentan con una distinción de calidad, las producciones «diferenciadas». En 1986 el vino con denominación de origen suponía algo menos de siete millones de hl, el $20 \%$ de la producción anual, siendo las principales marcas de vinos de calidad las de Jerez, Rioja, Valdepeñas y La Mancha. Al llegar el cambio de siglo se había duplicado el número de menciones (56) y su producción sobrepasaba los 12 millones de hl (30\% del vino), oscilando ya en la segunda década del XXI (años 2010-2013) entre los 17 y los 19 millones de hl, que se repartían en 131 menciones geográficas y representaban entre el 40 y el $50 \%$ de la producción total. 


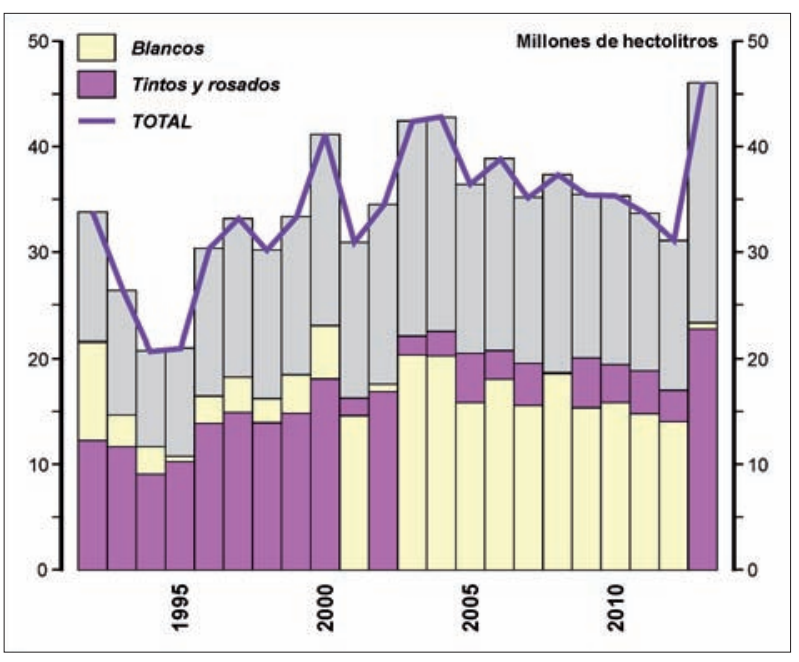

Fig. 5. Evolución de la producción de vino por tipos. Fuente: Ministerio de Agricultura, Alimentación y Medio Ambiente: Anuarios estadísticos.

\section{El Sistema de PROTECCIÓN DEL ORIGEN Y LA CALIDAD DE LOS VINOS EN ESPAÑA}

La denominación o indicación de origen es una señal distintiva que identifica un producto con su lugar de procedencia y lo diferencia de todos los demás. Ese mecanismo de distinción se ha aplicado a muchas producciones agroalimentarias para las que se han desarrollado normativas y procedimientos sobre la regulación, diferenciación y protección de bienes cuyas características están directamente relacionadas con su lugar de origen ${ }^{3}$.

Aunque los distintivos de calidad han adquirido particular importancia a partir de finales del siglo xx, la preocupación por diferenciar productos por su procedencia, salvaguardándolos de falsificaciones o imitaciones fraudulentas, data ya, al menos, de finales del siglo XIX, enmarcada en la búsqueda de protección de la propiedad industrial y los acuerdos internacionales en la materia $\mathrm{o}$, en términos más amplios, de la propiedad intelectual en su vertiente de salvaguardia de los signos distintivos entre los que se cuentan las indicaciones geográficas (Granados Aristizábal, 2012).

\footnotetext{
${ }^{3}$ Recientemente, el Parlamento Europeo aprobó una resolución favorable a la creación de un mecanismo unitario de protección de productos no agrícolas en la UE, con especial referencia a los artesanales, haciéndoles extensivo el sistema de indicaciones geográficas de los productos agroalimentarios. Resolución del Parlamento Europeo, de 6 de octubre de 2015, sobre la posible ampliación de la protección de las indicaciones geográficas de la Unión Europea a productos no agrícolas (2015/2053, INI).
}

Como uno de los primeros antecedentes de la defensa de los nombres geográficos se cita el Arreglo de Madrid relativo al registro internacional de las marcas, de 1891, que en su revisión de 1911 incluyó una mención expresa a las denominaciones de procedencia y, más en concreto, a las de los vinos. Precisamente para éstos se exceptuó la posibilidad, contemplada con carácter general, de considerarles un carácter genérico ${ }^{4}$, aunque tal salvedad no pudo evitar que durante mucho tiempo proliferaran sucedáneos (British Sherry, Australian Sherry, South African Sherry, imitando a los de Jerez) o se usurparan identidades, como en el caso del uso de las etiquetas de champagne o de cognac para bebidas obtenidas en lugares muy distintos al original de las marcas.

Pronto los países europeos se ocuparon de proteger con normativas nacionales sus producciones vinícolas. En España la primera disposición legal que incorpora las denominaciones de origen como instrumento de protección de nuestros vinos fue el Estatuto del Vino, promulgado como decreto en 1932 y elevado a rango de ley un año después. Previamente, a petición de los viticultores de La Rioja, y apoyándose en acuerdos internacionales y en la propia legislación sobre propiedad industrial y comercial, se había autorizado el uso de un precinto acreditativo de la procedencia de los vinos de la región riojana, creando un consejo regulador que ostentaría la representación de la marca y sería el responsable de proponer la delimitación de la zona acogida a la distinción colectiva Rioja y otros extremos reglamentarios sobre el uso de los derechos de protección y sobre la vigilancia de la utilización fraudulenta del nombre ${ }^{5}$.

El decreto de 1932 consagró su capítulo IV a las denominaciones de origen. Incorporando a nuestro derecho los principios del Convenio de Madrid y sus revisiones, estableció la protección de los nombres geográficos conocidos en el mercado nacional o extranjero, como empleados para la designación de vinos típicos que respondieran a unas características especiales de producción y a unos procedimientos de elaboración y crianza utilizados en la comarca o región de la que toman el nombre geográ-

\footnotetext{
${ }_{4}^{4}$ «Los Tribunales de cada país decidirán cuales son las Denominaciones que por razón de su carácter genérico se exceptúan de las disposiciones del presente Arreglo; no estarán sin embargo comprendidas en la reserva establecida por este artículo las Denominaciones regionales de procedencia de los productos vinícolas» (Unión Internacional para la protección de la propiedad industrial. Convenio de Unión de París de 20 de marzo de 1883 para la protección de la propiedad industrial, revisado en Bruselas el 14 de diciembre de 1900 y en Washington el 2 de junio de 1911. Gaceta de Madrid, 4 de julio de 1913).

${ }^{5}$ Gaceta de Madrid, 9 de julio de 1925, 29 de octubre de 1926, 9 de abril de 1928 .
} 


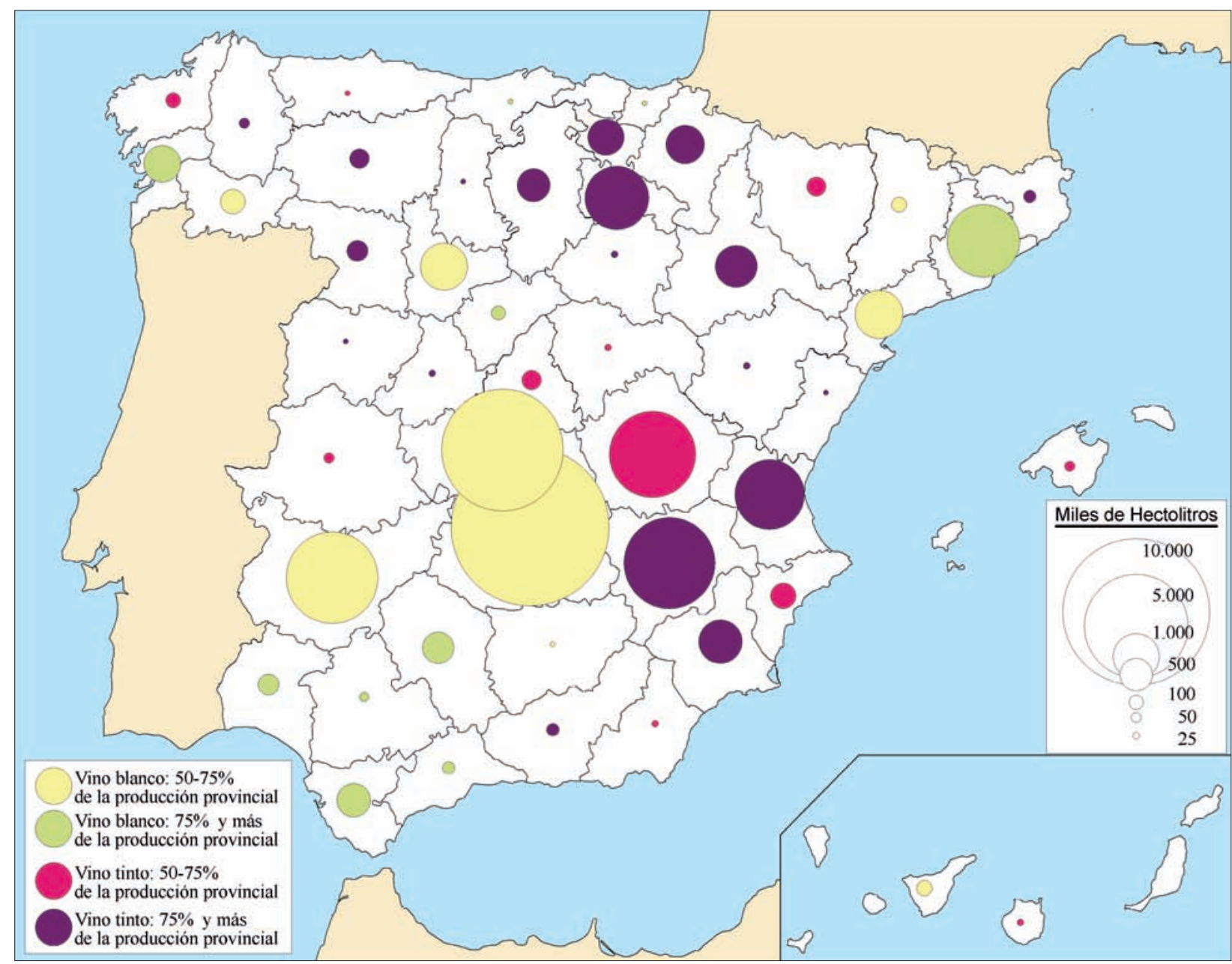

FIG. 6. Producción de vino por provincia y tipo predominante en cada una. Fuente: elaborado a partir de la información de Ministerio de Agricultura, Alimentación y Medio Ambiente: Anuario Estadístico 2014.

fico. Y, a renglón seguido, concedió amparo a diecinueve denominaciones (Rioja, Jerez-Xerez o Sherry, Málaga, Tarragona, Priorato, Panadés, Alella, Alicante, Valencia, Utiel, Cheste, Valdepeñas, Cariñena, Rueda, Rivero, Manzanilla-Sanlúcar de Barrameda, Malvasía-Sitjes, Noblejas y Conca de Barberá) dejando abierta la relación a la posible incorporación de nuevos «nombres geográficos protegidos». Cada denominación debería constituir un consejo regulador al que correspondería proponer el reglamento que delimitase las zonas vinícolas, los procedimientos de cultivo, las características de los vinos, etc.

$\mathrm{Al}$ dar fuerza de ley al Estatuto del Vino se añadieron a aquellas primeras denominaciones las de Montilla, Moriles, Mancha, Manzanares, Toro, Rueda, Navarra, Martorell, Extremadura, Huelva y Barcelona.
A pesar de contar tempranamente con un nutrido directorio de nombres geográficos de vinos, la efectividad de las denominaciones se dilató notablemente en el tiempo, al aplazarse para la mayor parte de ellas la aprobación de sus respectivos reglamentos. En el mismo periodo republicano únicamente se aprobaron los de Jerez-Xérès o Sherry, Manzanilla-Sanlúcar de Barrameda y Málaga, a los que en los años cuarenta siguieron los de Montilla-Moriles, Rioja y Tarragona y, en la década siguiente, Priorato, Alella, Utiel-Requena, Valencia, Alicante, Valdeorras y Ribeiro. Hasta 1970 se añadieron Jumilla, Cariñena, Penedés, Huelva, Valdepeñas, La Mancha y Navarra. Una veintena de denominaciones de origen efectivas en el momento en que se da por finalizada la vigencia del Estatuto del Vino y se aprueba la ley del Estatuto de la Viña, el Vino y los 
Alcoholes $^{6}$. Se argumentaba entonces la necesidad de una nueva ley tanto por razones de inadecuación de la anterior a los cambios habidos desde los años treinta como por la conveniencia de aproximar nuestra normativa a la de organismos internacionales en los que España participaba (Oficina Internacional de la Viña y el Vino) o aspiraba a pertenecer, como la Comunidad Europea, que en abril de aquel año estableció la Organización Común de Mercado (OCM) Vitivinícola y promulgó las primeras disposiciones sobre la protección del origen y la calidad de los vinos.

La ley, de diciembre de 1970, puso en marcha el Catastro Vitícola y Vinícola, creó el Instituto Nacional de Denominaciones de Origen (INDO) como organismo autónomo adscrito al Ministerio de Agricultura y abrió la vía para extender el reconocimiento de calidades diferenciadas «a aquellos productos agrarios cuya protección de calidad tenga especial interés económico o social», previsión cuyo desarrollo posterior fue ampliando el régimen de denominaciones a producciones agroalimentarias diversas: quesos, aceites y jamones curados (1974), judías secas, lentejas, garbanzos y arroz (1982), espárragos (1984), pimiento (1985), carnes frescas y embutidos curados (1987), productos agroalimentarios obtenidos sin el empleo de productos químicos en síntesis (1988), que un año después se convertiría en la denominación Agricultura Ecológica, miel, frutos secos, turrones, frutas de hueso, frutas de pepita, fresas, fresones, chufa y horchata (1990), berenjenas y salazones cárnicas (1993).

Como ocurriera con el vino, el desarrollo de estas otras denominaciones fue lento en sus inicios. A principios del 2000 el sistema protegía a 78 productos pero en 2014 ya eran 184 (Ministerio de Agricultura, 2014b); es decir, en los últimos quince años (2000-2014) la lista se engrosó con una media de más de siete declaraciones de calidad anuales. Igualmente las denominaciones de origen vinícolas aumentaron de manera muy rápida en los últimos años. A la veintena de 1970 se sumaron tan sólo 18 hasta 1990, pero veinte años después, en 2010, eran ya 85 , y 90 en 2016. Éstas, junto con 41 indicaciones geográficas protegidas y 16 bebidas espirituosas, componen las 131 indicaciones de calidad registradas ese año por el Ministerio de Agricultura ${ }^{7}$.

\footnotetext{
${ }^{6}$ Ley $25 / 1970$, de 2 de diciembre. La disposición transitoria primera de la ley, al relacionar las denominaciones entonces existentes para encomendar al Instituto Nacional de Denominaciones de Origen la presentación de una propuesta para reorganizarlas de acuerdo a la nueva normativa, cita también el nombre «Cheste», aunque parece que no llegó a contar con reglamento propio.

7 Marzo de 2016. <http://www.magrama.gob.es/es/alimentacion/temas/ calidad-agroalimentaria/calidad-diferenciada/dop $>$.
}

En 1970 quedó establecida una distinción entre la «denominación de origen» («el nombre geográfico de la región, comarca, lugar o localidad empleado para designar un producto procedente de la vid, del vino o los alcoholes de la respectiva zona, que tengan cualidades y caracteres diferenciales debidos principalmente al medio natural y a su elaboración y crianza»), la categoría superior de «denominación de origen calificada» y las denominaciones «genéricas»y «específicas», en virtud de la calidad, el método o el lugar de producción o de elaboración, o de las características de los derivados de la vid, del vino o los alcoholes. Más tarde se avanzó en la definición de los requisitos que debían cumplir las distintas modalidades de calidad: la «denominación específica» se aplica a productos diferenciados de los de su misma naturaleza por la materia prima utilizada, el medio natural o a los métodos de elaboración; la «denominación genérica» a los productos con caracteres comunes y especiales debidos a su naturaleza, a los sistemas de producción empleados o a los procedimientos de transformación, pudiendo producirse en todo el territorio nacional ${ }^{8}$. El primer reglamento de agricultura ecológica se formuló al amparo de una denominación genérica. Particular importancia tuvo la modalidad «denominación específica», creada para proteger productos de prestigio que no cumplían todas las condiciones para merecer el estatus de denominación de origen. El objetivo era que esos distintivos ampararan productos españoles con caracteres geográficos peculiares, si bien no estrictamente diferenciales, y ayudaran a su difusión.

Numerosas alimentos y bebidas recibieron la marca de denominación específica, identificada generalmente con un nombre geográfico ${ }^{9}$, lo que, en la práctica, restaba nitidez a la distinción entre esas denominaciones y las de origen, diferencia que radicaba en el grado mayor (denominación de origen) o menor (denominación específica) de vinculación a la zona delimitada. En el caso de los vinos su diferenciación con el rango de denominación específica constituyó una fase previa al reconocimiento de las respectivas denominaciones de origen.

Durante la segunda mitad de la década de 1980 las competencias en materia de agricultura fueron transfe-

\footnotetext{
${ }^{8}$ Real decreto $1573 / 1985$, de 1 de agosto, por el que se regulan las denominaciones genéricas y específicas de productos alimentarios; real decreto 728/1988, de 8 de julio, por el que se establece la normativa a que deben ajustarse las Denominaciones de Origen, Especificas y Genéricas de Productos Agroalimentarios no vínicos.

${ }^{9}$ El nombre de la denominación específica podía hacer referencia: a) al lugar geográfico de procedencia del producto amparado; b) a la raza o variedad productora de la materia prima; c) al método de elaboración, transformación o maduración
} 
ridas a las comunidades autónomas y, lo que resulta más importante para la configuración de los sistemas de calidad alimentaria, España se convirtió en miembro de pleno derecho de la Comunidad Europea, debiendo adaptar su sistema de protección de la calidad al vigente en aquel momento en la Comunidad para adoptar a partir de entonces, como derecho propio, el emanado de las instituciones comunitarias.

La protección de la calidad del vino en la Comunidad Europea se inicia en 1970 y parte del reglamento que sigue inmediatamente al que regula por primera vez la Organización Común del Mercado Vitivinícola ${ }^{10}$. Para armonizar criterios de exigencia de calidad y proteger a los productores de la competencia desleal y a los consumidores de las confusiones y los engaños se crea la marca europea Vino de Calidad Producido en una Región Determinada (VCPRD) ${ }^{11}$, como categoría diferenciada de los vinos de mesa, estableciendo prescripciones comunitarias para la mención. La revisión de la ocm en 1979 se acompañó de nueva normativa con disposiciones particulares relativas a los $\mathrm{VCPRD}^{12}$ : la delimitación de la zona de producción, la variedad de uva, los métodos de vinificación, el grado alcohólico, el rendimiento por hectárea y el sometimiento de los vinos a un examen analítico y organoléptico. Las condiciones concretas sobre exigencias a los VCPRD quedan, en general, a decisión de los estados miembros.

Para adaptar la comercialización de los productos vitivinícolas a las normas de la CEE, pocos meses después de promulgadas las disposiciones europeas de 1979 una orden ministerial reglamentaba el «uso de las indicaciones relativas a la calidad, edad y crianza de los vinos ${ }^{13} »$, introduciendo la mención «Vino de Calidad» (vc), aplicable a aquellos que ostentasen la categoría de denominación de origen o procediesen de alguna de las zonas vitivinícolas citadas en la propia orden; ésta también señala las variedades de uva recomendadas como más idóneas que habrán de utilizarse en la fabricación de los vinos en una proporción que alcance, al menos, el $60 \%$ de la uva empleada. Para que un vino de mesa sea declarado vC debe cumplir, además, condiciones especiales sobre homogeneidad y haber adquirido características en las que

\footnotetext{
${ }^{10}$ Reglamento (CEE) núm. 817/70 del Consejo, estableciendo disposiciones particulares relativas a los vinos de calidad producidos en regiones determinadas.

${ }^{11}$ Región determinada es «un área o un conjunto de áreas vitícolas que producen vinos que posean características de calidad particulares y cuyo nombre es utilizado para designar los vinos de calidad».

${ }^{12}$ Reglamento (CEE) núm. 338/79 del Consejo, estableciendo disposiciones particulares relativas a los vinos de calidad producidos en regiones determinadas.

13 Orden de 1 de agosto de 1979 (BOE, 31 de agosto de 1979).
}

resalten los aromas de las uvas de origen y las procedentes de su fermentación y maduración.

Incorporado nuestro país a la CEE, no se demoró la asunción de la mención europea $\mathrm{VCPRD}^{14}$. Además, haciendo uso de la previsión comunitaria sobre la implantación por los Estados miembros de indicaciones geográficas para designar vinos de mesa, ya en 1986 se establece la referencia «Vino de la Tierra». Las condiciones que se señalan para acceder a ella se refieren a su origen en las comarcas vitícolas que se relacionan en las disposiciones al efecto, al uso de determinadas variedades de uva y a su procedencia exclusivamente del territorio delimitado del que toma la denominación, ya que la distinción «Vino de la Tierra» debe ir acompañada del nombre de la comarca y/o municipio vitícola correspondiente, que no podrá coincidir con el asignado a los VCPRD.

A las nuevas regulaciones sobre la OCM vitivinícola aprobadas en 1987 y 1999 siguen sendos decretos incorporando las modificaciones introducidas por aquéllas y con las que se sigue completando el sistema de protección del origen y de la calidad diferenciada de los vinos españoles: reconocimiento de las menciones tradicionales «denominación de origen» y «denominación de origen calificada» alusivas a los VCPRD y el empleo de indicaciones geográficas en la designación de vinos de mesa, previo cumplimiento de determinadas condiciones.

Ese sistema se sistematizó en 2003 con la nueva ley de la Viña y el Vino que sustituyó a la promulgada en 1970, cuyo contenido había quedado desbordado por el desarrollo autonómico y por la legislación comunitaria, llegando a estar, a principios del siglo XXI, «sólo formalmente en vigor».

El sistema de protección se organizó en los siguientes niveles:

A) VINOS DE MESA

1. Vinos de mesa

2. Vinos de mesa con derecho a la mención tradicional «Vino de la Tierra»

B) Vinos de Calidad Producidos en una Región DeterMINADA (VCPRD)

1. Vinos de calidad con indicación geográfica

2. Vinos con denominación de origen

3. Vinos con denominación de origen calificada

4. Vinos de pagos

\footnotetext{
14 Orden de 11 de diciembre de 1986 por la que se establecen las reglas de utilización de nombres geográficos y de la mención «vino de la tierra» en la designación de los vinos de mesa.
} 
Los vinos con derecho a la mención «Vino de la Tierra», que vendrán identificados con una indicación geográfica, han de tener unas características específicas que deben a las condiciones ambientales y de cultivo en virtud de las cuales se delimita el territorio del que proceden.

Los vinos de calidad con indicación geográfica se identificarán con la mención «Vino de Calidad de», seguida del nombre del lugar donde se produzcan. Su calidad puede deberse al medio geográfico, al factor humano, o a ambos; factores de los que dependen las peculiaridades de la uva, de la elaboración del vino o de su envejecimiento.

La denominación de origen es un nombre geográfico que puede aplicarse a vinos que cumplan determinadas condiciones: la producción de uva y la elaboración deben tener lugar en la zona determinada a la que alude el nombre y sus características se deben fundamental o exclusivamente el medio geográfico, que en relación con este nivel de calidad está configurado por factores naturales y humanos. Para que un ámbito territorial (que incluirá tan sólo terrenos de especial aptitud para el cultivo de la vid) pueda obtener la denominación es necesario que antes haya producido, durante al menos cinco años, vino de calidad con indicación geográfica. Transcurridos diez años desde el reconocimiento como denominación de origen, la concesión, en su caso, de la distinción «calificada» exige que, además, el embotellado del producto se realice exclusivamente en bodegas (inscritas y ubicadas en la zona delimitada) en las que sólo tendrá entrada uva, mosto o vino de la misma zona y que se apruebe y ejecute para ellos un sistema de control a lo largo de la cadena productiva, hasta su salida al mercado. Debe contar también con la cartografía de los terrenos aptos para producir vinos con derecho a la denominación de origen calificada.

Son condiciones para obtener el reconocimiento de vino de pago que los vinos se hayan comercializado con el nombre del pago con una antigüedad mínima de cinco años, que toda la uva proceda de él y, con carácter general, que la elaboración y embotellado del vino se realicen por quienes ostenten la titularidad de los viñedos. El pago ${ }^{15}$ ha de tener una extensión limitada, a concretar, pero inferior a la de los términos municipales en los que se localice.

Dado que para cada nivel de protección se han de establecer rendimientos máximos por unidad de superficie,

15 «[...] paraje o sitio rural con características edáficas y de microclima propias que lo diferencian y distinguen de otros de su entorno, conocido con un nombre vinculado de forma tradicional y notoria al cultivo de los viñedos de los que se obtienen vinos con rasgos y cualidades singulares». en el supuesto de que una parcela sobrepase el umbral establecido para un nivel, la totalidad de su uva deberá destinarse a vino de otro nivel para el que cumpla los requisitos. La producción de una parcela puede destinarse en su totalidad a vino de un solo grado de protección o a vinos de distintos niveles, siempre que se cumplan los requisitos establecidos para cada uno ${ }^{16}$.

Con posterioridad a esa ley nuevos cambios en la normativa europea obligaron a introducir algunos retoques en el sistema de protección. Se trata, fundamentalmente de la implantación de una nueva regulación para los nombres geográficos de vinos, sustituyendo la anterior etiqueta de VCPRD por las menciones Denominación de Origen Protegida (DOP) e Indicación Geográfica Protegida (IGP).

- En el caso de los vinos, «Denominación de Origen» es el nombre de un territorio (comarca, región e, incluso, país) que los distingue por cumplir los siguientes requisitos: poseer una calidad y unas características ligadas básica o exclusivamente a un entorno geográfico particular, con los factores naturales y humanos que le son inherentes; y estar elaborado en ese territorio con uvas (sólo de la especie Vitis vinifera) producidas exclusivamente en él.

- En el caso de los vinos, «Indicación Geográfica Protegida» es el nombre de un territorio (comarca, región e, incluso, país) que los distingue por cumplir los siguientes requisitos: poseer una calidad, reputación u otras características atribuibles a su origen geográfico; y estar elaborado en ese territorio con uvas (pueden ser de la especie Vitis vinifera o de un cruce entre ésta y otras especies del género Vitis) producidas en él, al menos en un $85 \%$.

Se admitió, no obstante, el uso de los términos tradicionales de los países miembros, que en España eran los establecidos en la ley de 2003. El término tradicional que indica que un vino está acogido a una IGP es el de «Vino de la Tierra», mientras que los amparados por una DOP se identifican con las expresiones correspondientes a los subniveles de los antiguos vCPRD: Vino de Calidad de...,

\footnotetext{
${ }^{16}$ A título de ejemplo: el reglamento de la Do Navarra señala que «la producción máxima de uva admitida para los viñedos inscritos será de 8.000 kilogramos por hectárea». El pliego de condiciones de la indicación geográfica protegida «3 Riberas», cuya zona de producción coincide en parte con la DO Navarra, autoriza un rendimiento máximo de $16.000 \mathrm{~kg}$ de uva por ha.
} 
Cuadro III. Sistema de protección del origen y la calidad de los vinos

IGP Vino de la tierra Requisitos para la utilización de la mención tradicional «vino de la tierra» acompañada de una indicación geográfica:

1. deberán tenerse en cuenta, al menos, los siguientes aspectos:

a) categoría o categorías de vino a los que es aplicable la mención,

b) nombre de la indicación geográfica a emplear,

c) delimitación precisa del área geográfica comprendida,

d) indicación de las variedades de vid aptas,

e) graduación alcohólica volumétrica natural mínima de los diferentes tipos de vino con derecho a la mención,

f) una apreciación o una indicación de las características organolépticas,

g) el sistema de control aplicable a los vinos, que deberá realizar un organismo público o privado.

2. La utilización de una indicación geográfica para designar vinos resultantes de una mezcla de vinos procedente de uvas cosechadas en áreas de producción diferentes estará admitida si el 85 \%, como mínimo, del vino procede del área de producción de la que lleva el nombre.

DOP Denominación de origen (DO)

DOP Denominación de origen calificada (DOCa)

Nombre de una región, comarca, localidad o lugar delimitado que haya sido reconocido administrativamente para designar vinos que cumplan las siguientes condiciones:

- haber sido elaborados en la región, comarca, localidad o lugar determinados con uvas procedentes de los mismos,

- disfrutar de un elevado prestigio en el tráfico comercial en atención a su origen, y

- cuya calidad y características se deban fundamental o exclusivamente al medio geográfico que incluye los factores naturales y humanos.

Además de los requisitos exigibles a las denominaciones de origen, las «denominaciones de origen calificadas» deberán cumplir los siguientes:

- que hayan transcurrido, al menos, 10 años desde su reconocimiento como denominación de origen,

- que los productos amparados se comercialicen exclusivamente embotellados desde bodegas inscritas y ubicadas en la zona geográfica delimitada, y

- que dentro de su zona de producción, estén delimitados cartográficamente, por cada término municipal, los terrenos que se consideren aptos para producir vinos con derecho a la denominación de origen calificada.

DOP Vino de calidad con indicación geográfica (vino de calidad de)

DOP Vino de pago

DOP Vino de pago calificado
Vino producido en una región, comarca, localidad o lugar determinado con uvas procedentes de los mismos, cuya calidad, reputación o características se deban al medio geográfico, al factor humano o a ambos, en lo que se refiere a la producción de la uva, a la elaboración del vino o a su envejecimiento. Se identificarán mediante la mención «vino de calidad de», seguida del nombre de la región, comarca, localidad o lugar determinado donde se produzcan y elaboren.

Designa el paraje o sitio rural con características edáficas y de microclima propias que lo diferencian y distinguen de otros de su entorno, conocido con un nombre vinculado de forma tradicional y notoria al cultivo de los viñedos de los que se obtienen vinos con rasgos y cualidades singulares y cuya extensión máxima será limitada reglamentariamente por la Administración competente, de acuerdo con las características propias de cada comunidad autónoma. La extensión del «pago» no podrá ser igual ni superior a la de ninguno de los términos municipales en cuyo territorio o territorios se ubique. Se entiende que existe vinculación notoria con el cultivo de los viñedos cuando el nombre del pago venga siendo utilizado de forma habitual en el mercado para identificar los vinos obtenidos en aquél durante un período mínimo de cinco años. Toda la uva que se destine al vino de pago deberá proceder de viñedos ubicados en el pago determinado y el vino deberá elaborarse, almacenarse y, en su

En caso de que la totalidad del pago se encuentre incluida en el ámbito territorial de una denominación de origen calificada, podrá recibir el nombre de «vino de pago calificado», y los vinos producidos en él se denominarán «de pago calificado», siempre que acredite que cumple los requisitos exigidos a los vinos de la denominación de origen calificada y se encuentra inscrito en ésta. caso, criarse de forma separada de otros vinos.

Fuente: Reglamento (CE) núm. 607/2009 de la Comisión de 14 de julio de 2009 por el que se establecen determinadas disposiciones de aplicación del Reglamento (CE) núm. 479/2008 del Consejo en lo que atañe a las denominaciones de origen e indicaciones geográficas protegidas, a los términos tradicionales, al etiquetado y a la presentación de determinados productos vitivinícolas. Diario Oficial de la Unión Europea, 24.7.2009; Ministerio de Agricultura, Alimentación y Medio Ambiente, <http://www.magrama.gob.es>. 


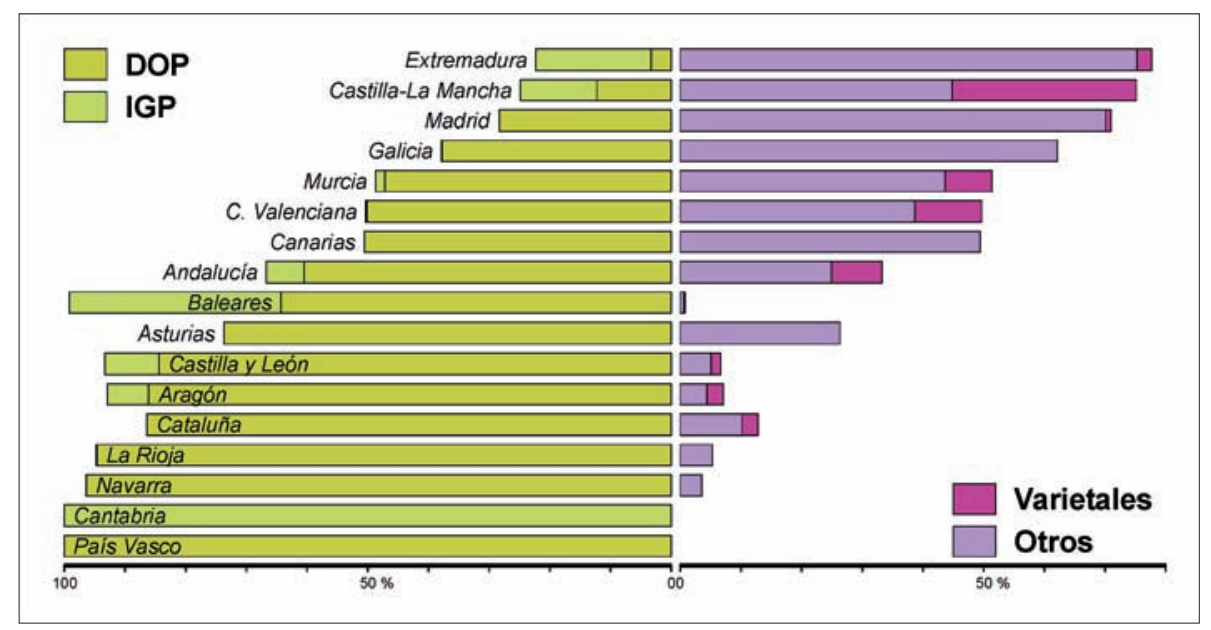

FIG. 7. Distribución de la producción de vino por modalidad de comercialización. Fuente: elaborado a partir de la información de Ministerio de Agricultura, Alimentación y Medio Ambiente: Anuario Estadístico 2014.
Denominación de Origen, Denominación de Origen Calificada, Vino de Pago.

De los cambios introducidos tal vez el más reseñable fue el que llevó a que vinos de mesa con la indicación de «Vinos de la Tierra de...», que estaban en el nivel inferior a los dotados de distinción diferenciada, hayan obtenido un reconocimiento comunitario como IGP, más próximo al que representa la DOP (Cuadro III).

\section{Denominaciones de origen E INDiCACiOneS GEOGRÁFICAS PROTEGIDAS DE LOS VINOS ESPAÑOLES}

El $94 \%$ de la superficie de viñedo está amparada por figuras de protección: 828.756 ha por denominaciones de origen y 76.211 por indicaciones geográficas protegidas. La proporción supera a la de la Unión Europea (83\%) y también a la de los principales países vitivinícolas, Francia $(88 \%)$ e Italia $(72 \%)$. La mitad del viñedo con indicación de calidad pertenece a Castilla-La Mancha, donde, al igual que en Castilla y León, La Rioja, el País Vasco, Baleares, Cantabria y Asturias, la totalidad del cultivo se enmarca en aquellas figuras; en las otras comunidades la protección abarca partes mayoritarias de los respectivos viñedos con la única excepción de Canarias, cuyas 11 denominaciones de origen cubren un tercio del espacio vitícola (Ministerio de Agricultura, 2015b).

En cambio, el vino comercializado con etiqueta de calidad diferenciada no alcanza la mitad del volumen producido anualmente. En 2013 los vinos con DO (15,3 millones de hl) y con IGP (4,4 millones) representaron el $43 \%$ de la producción. El $18 \%$ fueron vinos varietales y el $39 \%$ otros vinos (Ministerio de Agricultura, 2014a). La parte de cosecha calificada en el volumen anual de vino difiere mucho entre regiones vinícolas. En el País Vasco la totalidad de la producción pertenece a alguna de sus denominaciones; en Cataluña, Aragón, Castilla y León, La Rioja y Navarra es más del $75 \%$, y sobrepasa el $50 \%$ en la Comunidad Valenciana, Canarias, Andalucía y Asturias. En otras comunidades, incluida Castilla-La Mancha, que aporta la tercera parte de la producción calificada, la proporción es más modesta (Fig. 7).

Como ya se señaló, la mayor parte de las denominaciones se concedieron con posterioridad al ingreso de nuestro país en la Unión Europea. De las 90 actuales, en 1990 tan sólo existían 35, y de ellas 20 habían sido reconocidas en el republicano Estatuto del Vino, lo que da cuenta del escaso interés aplicado durante más de medio siglo. Una veintena más fueron aprobadas en la década de 1990 y otras 35 en los quince años transcurridos del siglo XXI. Catorce de estas últimas llevan la marca de vino de pago, el que ocupa la parte superior de la pirámide de calidad; sus zonas de producción se reducen a algunas decenas de hectáreas (sólo dos superan el centenar), con un único viticultor (excepcionalmente en uno de ellos hay tres viticultores) y una única bodega cuyo titular lo es también de los viñedos. Siete Dop tienen la distinción de vinos de calidad con indicación geográfica y dos (Rioja y Priorato) ostentan la condición de Do Calificada (Fig. 8).

Igualmente recientes son las menciones de indicación geográfica protegida, que se identifican como «Vino de la Tierra de...». Éstos fueron concebidos con un nivel de protección intermedio entre los vinos de mesa comunes y los de calidad diferenciada, pero en la actualidad, a condición de cumplir determinados requisitos como el de disponer de un pliego de condiciones, han ascendido a la consideración de indicaciones geográficas prote- 




FIG. 8. Zonas de producción amparadas por las denominaciones de origen protegidas de los vinos. Antigüedad en el reconocimiento de las menciones. Fuente: elaborado a partir de información diversa del Ministerio de Agricultura, Alimentación y Medio Ambiente (calidad agroalimentaria diferenciada) y de las páginas informáticas de las denominaciones.

gidas por las previsiones de la normativa comunitaria sobre equiparación de tal mención tradicional a la categoría de calidad europea. Muchos de los vinos de mesa (Valles de Zamora, Arlanza, Arribes del Duero) que adquirieron en la década de 1980 la categoría de vinos de la tierra están hoy amparados por una denominación de origen protegida.

Se han reconocido 41 indicaciones de extensión muy variable. Algunas incluyen todo el territorio de una comunidad (Castilla-La Mancha, Castilla y León, 

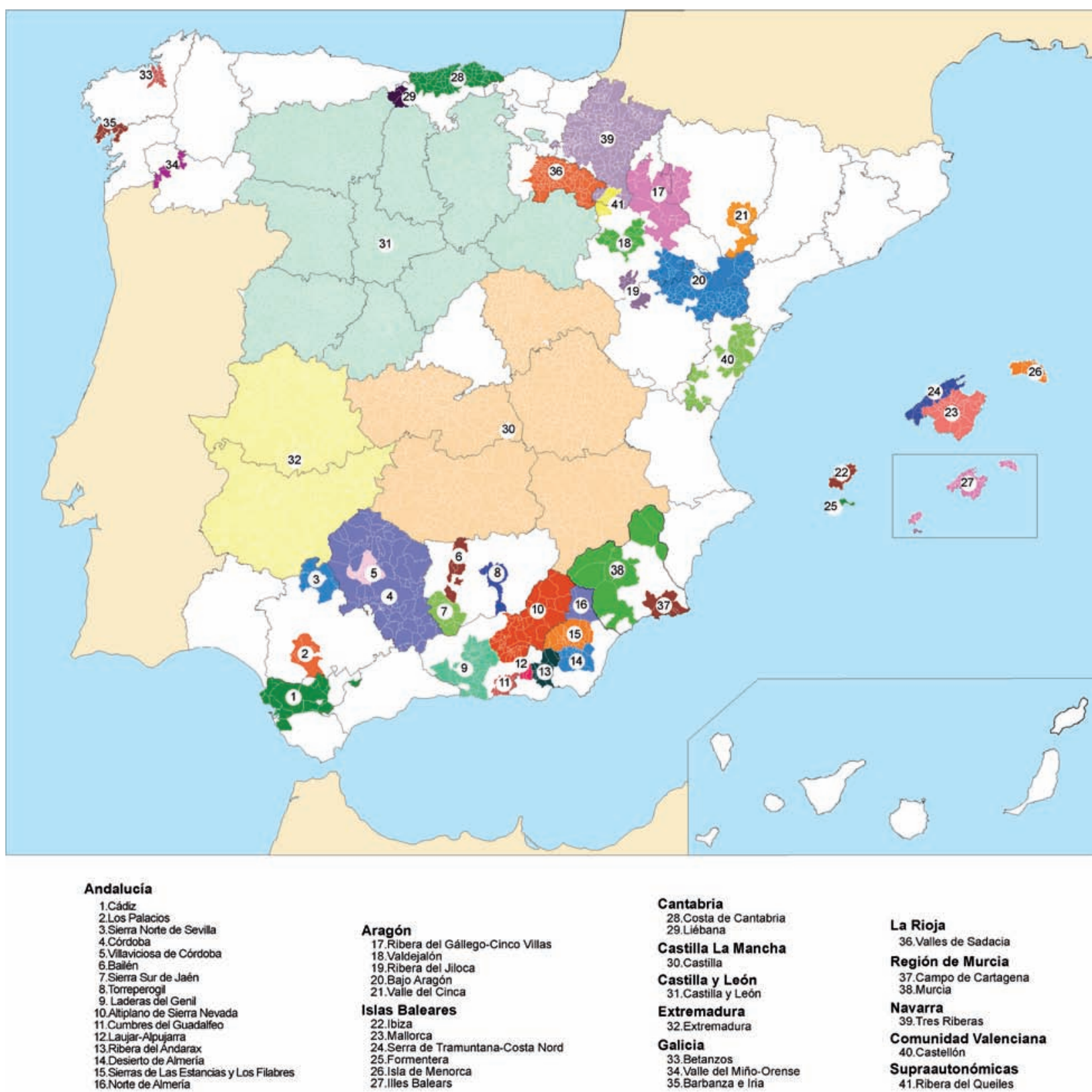

FIg. 9. Zonas de producción de los vinos de la tierra II. GG. PP. Fuente: elaborado a partir de información diversa del Ministerio de Agricultura, Alimentación y Medio Ambiente, calidad agroalimentaria diferenciada y de las páginas informáticas de las indicaciones geográficas protegidas.

Extremadura, Baleares), otras el de una provincia (Córdoba) y otras, sin embargo, el de una sola comarca o el perteneciente a unos pocos municipios. Se dan superposiciones de zonas de producción de distintos vinos de la tierra, por ejemplo, la Indicación Geográfica Villanueva de Córdoba abarca dos municipios que también se incluyen en la mención Córdoba y en la isla de Mallorca se superponen las indicaciones Illes Balears, Mallorca y Sierra Tramontana-Costa Nord. Ahora bien, la duplicidad de menciones más frecuente es la que afecta a municipios inscritos simultáneamente en una denominación de origen y en un área de producción de vino de la tierra. En este caso, cuando el vino no cumple con los requisitos de la DOP y sí con los establecidos para vino 
de la tierra puede ser comercializado bajo esta última mención.

En la actualidad, los vinos de la tierra compiten bien con los que tienen denominación de origen, sin estar sometidos a normas tan estrictas como los de estos últimos. Prueba de su éxito y de la confianza depositada en su futuro es la presencia en sus zonas de producción de algunas de las mayores empresas y más prestigiadas marcas, como González Byass y García Carrión, que sacan al mercado Vino de la Tierra de Castilla, o el Grupo Yllera y Romeral, en el Vino de la Tierra de Castilla y León (Fig. 9).

El registro de nombres protegidos de la Unión Europea recoge 1.291 vinos con denominación de origen. España ocupa el tercer lugar por número de menciones, precedida de Italia y Francia, con 474 y 376 denominaciones, respectivamente. Las indicaciones geográficas protegidas de vinos europeos son 458: 129 pertenecen a Italia, 116 a Grecia y 75 a Francia, siguiendo, en cuarto lugar, España, con sus 44 vinos de la tierra. ${ }^{17}$

Señalábamos antes que la superficie del viñedo integrado en denominaciones de origen e indicaciones geográficas protegidas alcanzaba en 2013 las 904.967 hectáreas, correspondientes a las zonas potencialmente aptas para la elaboración de vinos con DOP o IGP. Pero la suma de las superficies registradas por los organismos de control se queda por debajo de aquel total potencial, siendo en la campaña 2013-2014 de 676.322 ha, de las que en torno a la décima parte correspondían a vinos de la tierra (Ministerio de Agricultura, 2014c).

Entre las denominaciones de origen 16 tienen una superficie inscrita inferior a 100 ha, tratándose en su mayoría de vinos de pago; en 21 está entre 100 y 500 ha, y en 7 entre 500 y 1.000 . Estas 44 denominaciones (el $48 \%$ de las existentes) sólo suponen el 2,8\% de la superficie verificada por los consejos reguladores. En 32 menciones oscila entre 1.000 y 10.000 ha, acumulando el $21 \%$, y las catorce restantes, que sobrepasan en conjunto el medio millón de ha, concentran las tres cuartas partes de la superficie inscrita, sobresaliendo entre todas la Do La Mancha, con unas 160.000 ha, cien mil más que Rioja, que ocupa el segundo lugar (Fig. 10).

De las indicaciones geográficas protegidas la mitad cuentan con menos de cien hectáreas de viñedos inscritos y entre las cuarentena con menor superficie se reparten

${ }^{17}$ Comisión Europea. Agricultura y Desarrollo Rural, base de datos E-Bacchus. Este registro europeo contabiliza para España pero a costa de repetir en la relación algunas menciones. Depurado el registro de reiteraciones quedan las 90 menciones a las que nos hemos venido refiriendo.

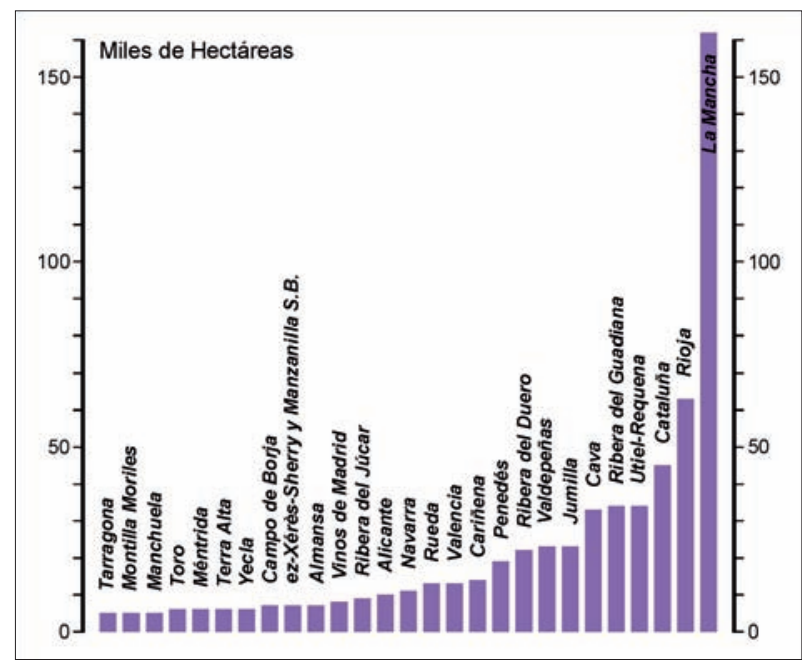

FIG. 10. Vinos con denominación de origen con más de 5.000 hectáreas de superficie inscrita (campaña 2013-2014). Fuente: elaborado a partir de Datos de las Denominaciones de Origen Protegidas de Vinos y Datos de las Indicaciones Geográficas Protegidas de Vinos-Vinos de la Tierra, del Ministerio de Agricultura, Alimentación y Medio Ambiente.

veinte mil hectáreas. El resto, cuarenta mil hectáreas, corresponden al Vino de la Tierra de Castilla, que encabeza la relación de los de su tipo sea cual sea el indicador que se considere: le corresponden unos cuatro mil viticultores de los 8.100 que suman los vinos con IGP para los que se cuenta con información, 209 bodegas de las 680 totales, una producción de 2,4 millones de hl de los 3,3 de estos vinos, y participa en proporciones similares tanto del volumen como del valor de los productos comercializados. La indicación «Extremadura» ocupa, aunque a distancia, la segunda posición, con 14.000 ha de superficie apta a final de campaña, 2.686 viticultores, 91 bodegas y 650.000 hl producidos. Los valores correspondientes al resto de los vinos de la tierra se quedan en niveles notablemente más bajos a falta de conocer los que corresponden a algunos de ellos ${ }^{18}$ (Fig. 11).

Los viticultores acogidos a las denominaciones de origen fueron en la misma campaña 125.300, algunos de ellos adscritos a más de una por superponerse determinadas zonas de producción (Cava y vinos de Rioja, Aragón, Navarra, Álava, Cataluña, Valencia y Extremadura; Cataluña y otras denominaciones catalanas; Málaga y Sierras de Málaga, Jerez y Manzanilla de Sanlúcar). La denomi-

\footnotetext{
${ }^{18}$ En los Datos de las Indicaciones Geográficas Protegidas (II. GG. PP.) de Vinos-Vinos de la Tierra no figura la información correspondiente a Campo de Cartagena, Castilla y León, Norte de Almería y Villaviciosa de Córdoba.
} 


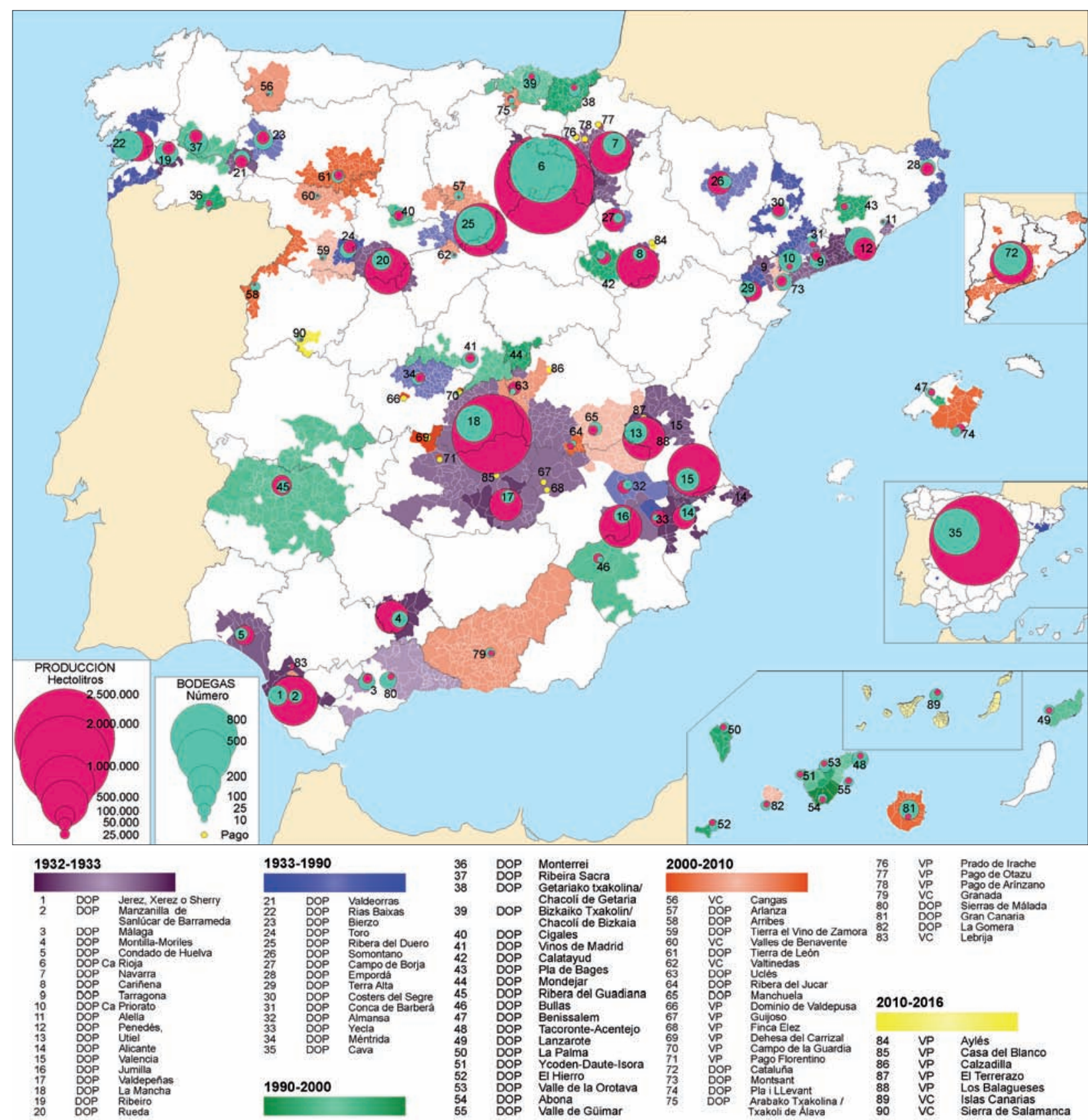

FIg. 11. Bodegas inscritas y producción de vino en las distintas denominaciones de origen. Fuente: elaborado a partir de Ministerio de Agricultura, Alimentación y Medio Ambiente, Datos de las Denominaciones de Origen Protegidas de Vinos y de las Indicaciones Geográficas Protegidas de Vinos-Vinos de la Tierra.

nación de origen con mayor número de productores es Rioja, con 16.400 , a la que sigue de cerca La Mancha. Ninguna otra se aproxima a las anteriores. Ribera del Duero cuenta con 8.300 y otras seis (Cataluña, Valencia, Cava, Rías Baixas, Ribeiro y Utiel-Requena) superan los 5.000. La mayor parte de las denominaciones tiene menos de mil viticultores, estando ocupados los últimos lugares de la relación por los vinos de pago, que, salvo en un caso, tienen adscrito un solo viticultor. A pesar de su escasa extensión, es en estos vinos donde se alcanza la 
Cuadro IV. Datos básicos de las denominaciones de origen e indicaciones geográficas protegidas de los vinos

\begin{tabular}{|c|c|c|c|c|c|c|c|c|c|c|}
\hline & \multicolumn{5}{|c|}{ Vinos con denominación de origen } & \multicolumn{5}{|c|}{$\begin{array}{c}\text { Vinos con indicación geográfica protegida- } \\
\text { Vinos de la tierra }\end{array}$} \\
\hline & $\begin{array}{c}\text { DOP } \\
\text { N. } .^{\circ}(1)\end{array}$ & $\begin{array}{c}\text { Superficie } \\
\text { inscrita Ha (2) }\end{array}$ & $\begin{array}{l}\text { Viticultores } \\
\text { N. }^{\circ}(2)\end{array}$ & $\begin{array}{l}\text { Bodegas } \\
\text { N. }{ }^{\circ}(2)\end{array}$ & $\begin{array}{l}\text { Producción } \\
\text { Hl (2) }\end{array}$ & $\begin{array}{l}\text { IGP } \\
\text { N. }{ }^{\circ}\end{array}$ & $\begin{array}{l}\text { Superficie } \\
\text { inscrita } \mathrm{Ha}\end{array}$ & $\begin{array}{l}\text { Viticultores } \\
\text { N. }{ }^{\circ}\end{array}$ & $\begin{array}{l}\text { Bodegas } \\
\text { N. }{ }^{\circ}\end{array}$ & $\begin{array}{c}\text { Producción } \\
\mathrm{Hl}\end{array}$ \\
\hline Andalucía & 8 & 15.985 & 5.946 & 240 & 1.044 .250 & 16 & 2.303 & 970 & 63 & 86.438 \\
\hline Aragón & 6 & 29.022 & 3.997 & 96 & 858.457 & 6 & 2.018 & $\mathrm{NC}$ & 32 & 65.041 \\
\hline Asturias & 1 & 28 & 47 & 5 & 842 & - & - & - & - & - \\
\hline Baleares (3) & 2 & 1.004 & 185 & 28 & 31.470 & 6 & 733 & 246 & 60 & 22.484 \\
\hline Canarias & 11 & 6.175 & 8.772 & 291 & 45.544 & - & - & - & - & - \\
\hline Cantabria & - & - & - & - & - & 2 & 57 & 51 & 11 & 928 \\
\hline C.-La Mancha (4) & 17 & 262.739 & 23.726 & 408 & 2.216 .485 & 1 & 42.205 & 3.958 & 209 & 2.424 .008 \\
\hline C. y León & 12 & 48.751 & 15.340 & 599 & 1.358 .169 & 1 & $\mathrm{~S} / \mathrm{d}$ & $\mathrm{S} / \mathrm{d}$ & 173 & $\mathrm{~S} / \mathrm{d}$ \\
\hline Cataluña & 11 & 43.811 & 9.055 & 576 & 2.580 .902 & - & - & - & - & - \\
\hline C. Valenciana & 6 & 56.815 & 14.480 & 240 & 1.196 .717 & 1 & 226 & 100 & 14 & 650.245 \\
\hline Extremadura & 2 & 34.051 & 3.135 & 25 & 112.625 & 1 & 14.001 & 2.686 & 91 & 4.699 \\
\hline Galicia & 5 & 9.641 & 16.650 & 449 & 352.738 & 3 & 24 & 39 & 15 & 1.027 \\
\hline La Rioja & 2 & 42.971 & 12.232 & 424 & 2.260 .960 & 1 & 129 & 9 & 2 & 15.190 \\
\hline Madrid & 1 & 8.391 & 2.891 & 44 & 24.586 & - & - & - & - & - \\
\hline Murcia & 3 & 22.257 & 1.908 & 38 & 331.923 & 2 & 382 & 31 & 2 & 13.124 \\
\hline Navarra & 5 & 18.351 & 3.844 & 132 & 622.959 & 2 & 46 & 8 & 8 & 2.256 \\
\hline País Vasco & 4 & 14.206 & 3.092 & 440 & 835.250 & - & - & - & - & - \\
\hline TOTAL (5) & 90 & 614.198 & 125.300 & 4.035 & 13.873 .877 & 40 & 62.124 & 8.098 & 680 & 3.285 .440 \\
\hline \multicolumn{5}{|c|}{$\begin{array}{l}\text { (1) Hay tres vinos con Do cuyas áreas de producción se extienden } \\
\text { por dos o más comunidades autónomas: Cava (Cataluña, La Rioja, } \\
\text { Aragón, P. Vasco, Navarra, C. Valenciana y Extremadura), Jumilla } \\
\text { (Castilla-La Mancha y Murcia) y Rioja (La Rioja, Navarra y Pañis } \\
\text { Vasco). } \\
\text { (2) La información de la fuente utilizada se refiere a las } 90 \text { DD. oo. } \\
\text { En los vinos señalados en (1) se distribuyeron hectáreas, viticulto- } \\
\text { res, bodegas y volúmenes producidos y comercializados como sigue: } \\
\text { para la Do Rioja se tomó la información, desglosada por comunida- } \\
\text { des autónomas de El Rioja en cifras, estadísticas } 2013 \text {, del Consejo } \\
\text { Regulador de la Denominación de Origen Calificada Rioja; en Ju- } \\
\text { milla se distribuyeron los valores totales de la DO a razón de } 60 \% \\
\text { atribuidos a Castilla-La Mancha y } 40 \text { \% a Murcia por ser ésas las } \\
\text { proporciones en que se reparte la zona de producción (DOP Jumilla, } \\
\text { <http://vinosdejumilla.org/dop-jumilla>); en el Cava la distribución } \\
\text { atendió también a la que tiene la zona de producción, aunque sólo } \\
\text { para las variables producción y comercialización, ya que la superficie } \\
\text { inscrita, los viticultores y las bodegas se comparten con otras DD. oo. }\end{array}$} & \multicolumn{6}{|c|}{$\begin{array}{l}\text { (3) Los Datos de las denominaciones de origen protegidas de vinos } \\
\text { (DOPS), campaña 2013-2014, recogen una producción de } 512.809 \mathrm{hl} \\
\text { en la Do balear Pla i Llevant. El error ronda el medio millón de hl, } \\
\text { habiendo consignado } 12.809 \mathrm{hl} \text {, en consonancia con la información } \\
\text { de la propia denominación que señala producciones de entre } 11.000 \\
\text { y } 14.000 \mathrm{hl} \text { en los últimos años (<http://www.doplaillevant.com// } \\
\text { doplailllevant.php }>\text { ). } \\
\text { (4) En sentido contrario, la producción calificada de vino La } \\
\text { Mancha que figura en los Datos de las denominaciones de origen } \\
\text { protegidas de vinos (DOPs), campaña } 2013-2014 \text {, es de } 562.456 \mathrm{hl} \text {. } \\
\text { Hemos estimado que la cifra más aproximada, de acuerdo con la } \\
\text { información del Consejo Regulador (<http://lamanchawines.com/ } \\
\text { es>), es un millón más de ha, es decir, 1.562.456. } \\
\text { (5) No se han sumado las superficies, viticultores y bodegas de } \\
\text { Manzanilla-Sanlúcar de Barrameda, Sierras de Málaga y Cataluña } \\
\text { (además del Cava, como se dijo en [2]) por coincidir con las de } \\
\text { Jerez-Xérès-Sherry, Málaga y diversas DD. oo. catalanas, respecti- } \\
\text { vamente. }\end{array}$} \\
\hline
\end{tabular}

relación hectáreas/productor más alta; en el resto sólo se superan las 10 ha/viticultor en Jumilla, Ribera del Guadiana y La Mancha. En la mayor parte ellos no se llega a las 5 ha por viticultor, y en los vinos gallegos y canarios ni siquiera a 1 ha.

En lo que respecta al vino con denominación de origen, la producción de Rioja fue muy superior a cualquier otra, situándose entre los 2,5 y los 2,7 millones de hl ${ }^{19}$, en torno a la quinta parte del total. La Mancha obtuvo 1,5 millones de hl, y Valencia, Ribera del Duero, Rueda, Ca-

\footnotetext{
${ }^{19}$ Información del Ministerio de Agricultura y del Consejo Regulador en su página informática, respectivamente.
} 
Cuadro V. El subsector vinícola en la industria alimentaria

\begin{tabular}{|c|c|c|c|c|c|c|c|c|}
\hline & \multicolumn{3}{|c|}{ Empleo, N. ${ }^{\circ}$} & \multicolumn{3}{|c|}{ Venta de productos, millones de euros } & \multicolumn{2}{|c|}{$\begin{array}{l}\text { Valor añadido por persona } \\
\text { ocupada, miles de euros }\end{array}$} \\
\hline & (A) & (B) & & (C) & (D) & & & \\
\hline & $\begin{array}{l}\text { Industria } \\
\text { vinícola }\end{array}$ & $\begin{array}{c}\text { Industria } \\
\text { alimentaria }\end{array}$ & $\mathrm{A} / \mathrm{B}, \%$ & $\begin{array}{l}\text { Industria } \\
\text { vinícola }\end{array}$ & $\begin{array}{c}\text { Industria } \\
\text { alimentaria }\end{array}$ & $\mathrm{C} / \mathrm{D}, \%$ & $\begin{array}{l}\text { Industria } \\
\text { vinícola }\end{array}$ & $\begin{array}{c}\text { Industria } \\
\text { alimentaria }\end{array}$ \\
\hline Andalucía & 1.574 & 47.118 & 3,3 & 290 & 12.468 & 2,3 & 46 & 48 \\
\hline Aragón & 888 & 10.209 & 8,7 & 211 & 3.435 & 6,1 & 48 & 34 \\
\hline Asturias & 56 & 7.229 & 0,8 & 3 & 1.745 & 0,2 & 33 & 50 \\
\hline Baleares & 234 & 3.769 & 6,2 & 26 & 553 & 4,7 & 61 & 20 \\
\hline Canarias & 290 & 9.555 & 3 & 21 & 1.180 & 1,8 & 28 & 46 \\
\hline Cantabria & 7 & 6.136 & 0,1 & 0 & 1.188 & 0 & 20 & 39 \\
\hline Castilla y León & 3.636 & 35.476 & 10,2 & 590 & 9.049 & 6,5 & 66 & 61 \\
\hline Castilla-La Mancha & 3.227 & 23.270 & 13,9 & 1.416 & 7.537 & 18,8 & 72 & 71 \\
\hline Cataluña & 5.154 & 75.315 & 6,8 & 1.192 & 20.671 & 5,8 & 64 & 55 \\
\hline C. Valenciana & 1.325 & 30.814 & 4,3 & 372 & 7.899 & 4,7 & 37 & 58 \\
\hline Extremadura & 658 & 9.270 & 7,1 & 275 & 1.984 & 13,8 & 41 & 42 \\
\hline Galicia & 1.157 & 28.682 & 4 & 179 & 7.220 & 2,5 & 36 & 44 \\
\hline Madrid & 165 & 17.158 & 1 & 5 & 3.852 & 0,1 & 68 & 53 \\
\hline Murcia & 348 & 19.278 & 1,8 & 74 & 5.018 & 1,5 & 50 & 54 \\
\hline Navarra & 866 & 11.313 & 7,65 & 130 & 2.615 & 4,95 & 52 & 49 \\
\hline País Vasco & 2.348 & 13.994 & 16,8 & 453 & 3.381 & 13,4 & 80 & 57 \\
\hline La Rioja & 2.605 & 6.955 & 37,5 & 767 & 1.752 & 43,8 & 98 & 70 \\
\hline Total & 24.538 & 355.541 & 6,90 & 6.004 & 91.547 & 6,56 & 65 & 54 \\
\hline Total $\mathrm{n} .^{\circ}$ industrias & 4.052 & 28.278 & & & & & & \\
\hline $\begin{array}{l}\text { Fuente: elaborado a } \\
\text { industria alimentari } \\
\text { ca-sobre-la-industria }\end{array}$ & $\begin{array}{l}\text { de Magra } \\
\text { 14-2015, } \\
\text { alimentar }\end{array}$ & $\begin{array}{l}\text { Información } \\
\text { p://www.mą }\end{array}$ & $\begin{array}{l}\text { nómicas } \\
\text { na.gob.es }\end{array}$ & $\begin{array}{l}\text { e la industr } \\
\text { /alimentacic }\end{array}$ & $\begin{array}{l}\text { groalimentari } \\
\text { emas/industria }\end{array}$ & $\begin{array}{l}\text { datos CC. } \\
\text { groalimen }\end{array}$ & $\begin{array}{l}\text { A. año } 2013 \text {, } \\
\text { aria/informa }\end{array}$ & $\begin{array}{l}\text { nforme anual } \\
\text { lon-economi- }\end{array}$ \\
\hline
\end{tabular}

riñena y Jerez-Xérès-Sherry y Manzanilla S. B. (conjuntamente estos últimos), entre 0,5 y 1 millón de hl. Estas siete denominaciones (7,2 millones de hl) reúnen más de la mitad de todo el vino con esa calificación. Si añadimos los más de dos millones de hl de Cava, la proporción correspondiente a las denominaciones más productoras se acrecienta considerablemente (véase distribución de magnitudes sobre DD. OO. e II. GG. PP. de los vinos en el Cuadro IV).

\section{LA INDUSTRIA VINÍCOLA. EL SECTOR BODEGUERO}

De las fuentes existentes, pese a sus discrepancias, puede deducirse que el primer eslabón de la cadena de producción del vino, la «fase agraria», está muy atomizado, aunque los datos generales esconden, en realidad, la verdadera situación del sector, caracterizada por una estructura dual en la que conviven muchas explotaciones de dimensiones reducidas, que apenas permiten la profesionalización del cultivo, con un pequeño grupo de ellas que poseen un tamaño suficiente para estar bien mecanizadas y obtener elevadas producciones (Ministerio de Agricultura, 2003).

Fragmentación y dualidad se reproducen en el escalón industrial. En 2009 se calculaba que existían en España entre 6.800 y 7.200 bodegas $^{20}$, número que fue reduciéndose en los años siguientes. A comienzos de la segunda década de este siglo estaban registradas 5.464 (Cooperativas Agroalimentarias, 2011), en 2014 se estimaba que «algo más de 4.000 bodegas elaboran en España vinos tranquilos, espumosos y de licor» (Icex, 2014) y en 2015 se cifraban en 4.052 (Ministerio de Agricultura, 2015c). En ese último año, las bodegas representaban el 14,3\% de

${ }^{20}$ Denominación de Origen Utiel-Requena. Reconoce las dificultades para conocer con exactitud el censo de bodegas porque no todas las zonas productoras llevan ese censo ni todos los establecimientos forman parte de las distintas asociaciones del ramo. <http://utielrequena.org/las-bodegas-de-vino-en-espana>. 
Cuadro VI. Cooperativas vitivinícolas. Magnitudes básicas por comunidades autónomas

\begin{tabular}{|c|c|c|c|c|c|c|}
\hline & $\begin{array}{l}\text { (A) } \\
\text { N. }\end{array}$ & $\begin{array}{c}\text { (B) } \\
\text { Socios }\end{array}$ & $\begin{array}{c}\text { (C) } \\
\text { Facturación, } \\
\text { miles de euros }\end{array}$ & $\mathrm{B} / \mathrm{A}$ & $\mathrm{C} / \mathrm{A}$ & $\begin{array}{c}\text { Coop. } \\
\text { 2. }{ }^{\circ} \text { grado }\end{array}$ \\
\hline Andalucía & 36 & 13.585 & $67.751,6$ & 377 & 1.881 .990 & 2 \\
\hline Aragón & 36 & 11.672 & $77.783,8$ & 324 & 2.160 .662 & \\
\hline I. Baleares & 3 & 12 & 103,2 & 4 & 34.406 & \\
\hline C. y León & 36 & 8.719 & $67.736,5$ & 242 & 1.881 .568 & 1 \\
\hline C.-La Mancha & 254 & 92.554 & $574.753,7$ & 364 & 2.262 .810 & 8 \\
\hline Cataluña & 75 & 21.502 & $97.940,3$ & 286 & 1.305 .870 & 2 \\
\hline C. Valenciana & 69 & 32.124 & $77.952,2$ & 465 & 1.129 .742 & 3 \\
\hline Extremadura & 23 & 9.675 & $48.317,2$ & 420 & 2.100 .749 & 1 \\
\hline Galicia & 10 & 2.507 & $25.580,5$ & 251 & 2.558 .052 & \\
\hline C. Madrid & 13 & 3.904 & $4.250,1$ & 300 & 326.923 & \\
\hline R. de Murcia & 3 & 2.328 & $9.864,7$ & 776 & 3.288 .240 & \\
\hline Navarra & 29 & 4.697 & $44.549,8$ & 162 & 1.536 .200 & 2 \\
\hline País Vasco & 7 & 544 & $11.836,3$ & 78 & 1.690 .906 & \\
\hline La Rioja & 34 & 6.949 & $103.597,5$ & 204 & 3.046 .986 & \\
\hline TOTAL & 628 & 210.772 & $1.212 .017,7$ & 335 & 1.929 .964 & 19 \\
\hline
\end{tabular}

las empresas alimentarias, pero su ocupación y sus ventas sólo significaban el $7 \%$ de las del sector. Ello suponía que el tamaño medio de las primeras fuese mucho menor que el de las segundas, tanto si se medía en número de trabajadores (6 en las bodegas y 12,5 en el conjunto del sector) como si se hacía en volumen de facturación, 1,48 y 3,22 millones de euros respectivamente (Cuadro V).

Por comunidades, destaca el peso de Cataluña, donde se concentra, aproximadamente, el $25 \%$ del empleo y del valor de la producción, tanto del sector alimentario como del subsector vinícola. Visto, en cambio, desde la importancia que adquieren las bodegas en las economías regionales, sobresalen el País Vasco, Castilla y León, CastillaLa Mancha y, sobre todo, La Rioja. En este último caso la industria vinícola aporta el $37 \%$ del empleo y el $43 \%$ del valor de su industria alimentaria.

Junto a la mencionada dualidad que representa la coexistencia de un nutrido número de empresas de reducidas dimensiones y algunas grandes compañías con volúmenes importantes de producción y empleo y con facturaciones elevadas, una segunda característica es la importancia del sector cooperativo. Con referencia a 2004 la Confederación de Cooperativas Agrarias de España (hoy Cooperativas Agroalimentarias) habla de unos 200.000 viticultores asociados (el $18 \%$ de los cooperativistas agroalimentarios), con el $40 \%$ de las explotaciones vitícolas. Reunían además el $58 \%$ del viñedo, y aportaban el $65 \%$ de la uva de vinificación y el $60 \%$ del vino elaborado. Su contribución era mucho menor en el ámbito de los vinos embotellados (CCAE, 2004).

A principios de siglo se estimaba en unas 800 el número de bodegas inscritas como cooperativas o sociedades agrarias de transformación (CCAE, 2004); una década después funcionaban unas 630, y en 2013, 538 (Cooperativas Agroalimentarias, 2011 y 2016), siendo el cuarto subsector alimentario por número de entidades (tras suministros, aceite de oliva y frutas y hortalizas) y el sexto por facturación $(7,2 \%)$, por detrás de los ya citados y de los de alimentación animal y cultivos herbáceos. Se deduce de lo anterior el menor grado de concentración de las cooperativas vinícolas, sin que ello se vea paliado por una organización del tejido asociativo en cooperativas de segundo grado, ya que éstas están en torno a la veintena, una por cada 33 de las de primer grado.

En 2010, el $40 \%$ de las cooperativas vinícolas y el $44 \%$ de los viticultores asociados se encontraban en Castilla-La Mancha, donde se obtenía también el $47 \%$ de la facturación. Pero las de mayor dimensión media, tanto en número de socios como en ventas, desarrollaban su actividad en las denominaciones de origen murcianas (Jumilla, Bullas, Yecla). Tras éstas se encontraban, por facturación media, las cooperativas riojanas (Cuadro VI). 


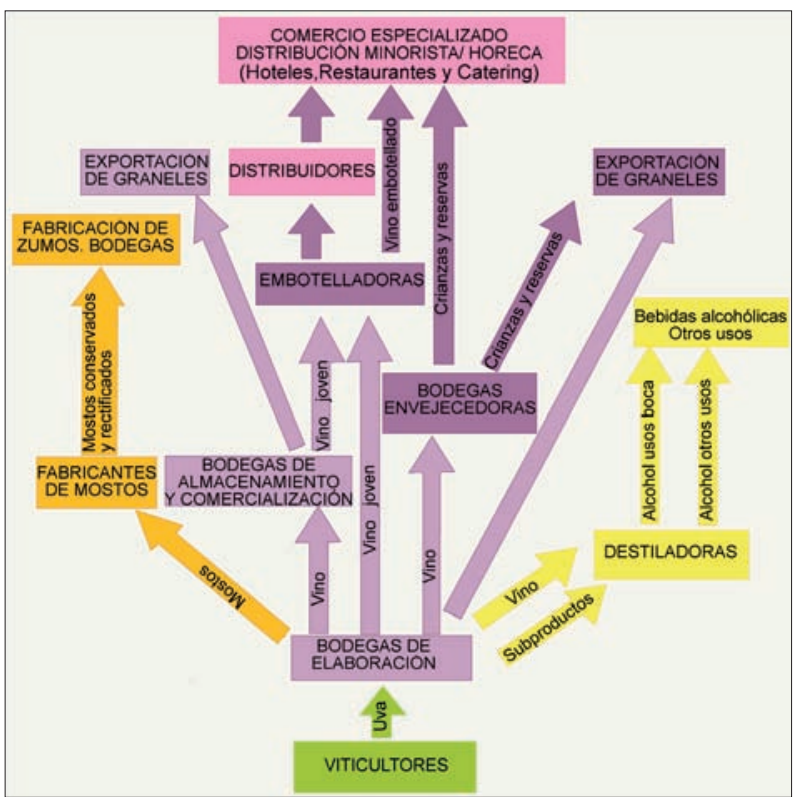

FIg. 12. Estructura industrial del subsector de vinos Fuente: Ministerio de Agricultura, Pesca y Alimentación: Diagnóstico y Análisis Estratégico del Sector Agroalimentario Español. Análisis de la cadena de producción y distribución del sector del vino (fecha aproximada: 2005).

El peso de las cooperativas y la proliferación de bodegas con producción agrícola propia hacen que el mercado de uva sólo absorba entre el $20 \%$ y el $25 \%$ de la cosecha, el $80 \%$ restante está integrada verticalmente con la producción de vino. La integración pierde intensidad entre la elaboración y el envejecimiento y/o embotellado, generándose, por tanto, un voluminoso mercado de graneles, que puede estimarse en el $70 \%$ del vino elaborado y en el que participan más los vinos de mesa que los que cuentan con alguna mención de calidad diferenciada (Langreo, 2006).

Realizado el exprimido de la uva con el jugo, pueden obtenerse tres tipo de productos:

- Los mostos, utilizados con posterioridad en la fabricación de vino o de zumo.

- Los alcoholes, obtenidos mediante destilación, destinados a producir bebidas alcohólicas y otros productos (combustibles, farmacéuticos).

- Los vinos, espumosos y tranquilos, con distintos niveles de graduación alcohólica, que constituyen la parte más voluminosa.

La elevada estacionalidad de la producción del jugo de uva obliga a los productores, y también a otros mayoristas, a disponer de una gran capacidad de almacenaje
Cuadro VII. Las diez primeras empresas del sector del vino, 2013

\begin{tabular}{|c|c|c|}
\hline Empresas & $\begin{array}{l}\text { Ventas } \\
\text { M. } €\end{array}$ & Empleo \\
\hline 1 J. García Carrión, S. A. & 810 & 800 \\
\hline 2 Freixenet, S. A. (Grupo) & 527 & 1.874 \\
\hline 3 Félix Solís Avantis, S. A.-Grupo & 250 & 396 \\
\hline 4 Grupo Osborne, S. A.* & 232 & 850 \\
\hline 5 Codorniu, S. A. (Grupo) & 232 & 900 \\
\hline 6 Miguel Torres, S. A. (Grupo) & 230 & 1.306 \\
\hline 7 Félix Solís, S. A. González Byass, S. A. Grupo* & 214 & 531 \\
\hline 8 United Wineries España, S. A. (Grupo Arco) & 160 & 150 \\
\hline 9 Pernod Ricard Winemakers Spain (Grupo) & 120 & 400 \\
\hline 10 Barón de Ley, S. A. & 82 & 182 \\
\hline Total & 2.857 & 7.389 \\
\hline$\%$ sobre el sector & 47 & 30 \\
\hline \multicolumn{3}{|c|}{$\begin{array}{l}\text { Fuente: Magrama: Informe sobre la industria agroalimentaria. Sec- } \\
\text { tor vinos } 2015 \text {. }\end{array}$} \\
\hline * Los datos incluyen líneas de negocio en otros & sectore & \\
\hline
\end{tabular}

que sumada alcanza una cifra aproximada de unos $50 \mathrm{mi}-$ llones de hectolitros.

Obtenido el vino a partir de la fermentación de los mostos, aquél puede ser vendido a granel, embotellado (por la propia bodega o por otra dedicada exclusivamente a este fin) o traspasado a barrica. El vino embotellado es el denominado «joven» o «del año»; el introducido en barrica, el «envejecido». Casi todas las bodegas envejecen al menos una parte de su producción (especialmente cuantiosa en las acogidas a denominación de origen), sacando al mercado vinos que dependiendo del tiempo de permanencia en la barrica y en la botella adquieren categorías como las de «roble» (o semicrianza), «crianza», «reserva» o «gran reserva» (Fig. 12).

En el sistema de soleras, y con referencia concreta al Marco de Jerez, la integración viticultura-elaboración de vino es también muy alta. En 2002 las bodegas (comercializadoras y no comercializadoras) contaban con más del $40 \%$ del viñedo inscrito en las denominaciones de origen, cultivado en explotaciones grandes y mecanizadas. Los pequeños viticultores asociados a cooperativas (que realizan el prensado, suministrando el mosto a las bodegas) concentraban el $33 \%$. El resto correspondía a los productores que venden la uva a las bodegas (Junta de Andalucía, 2002).

Con independencia de los grupos bodegueros que disponen de instalaciones para cubrir el proceso completo, desde la elaboración a la expedición, la norma que regula las denominaciones de origen de ese ámbito, Jerez- 
Cuadro VIII. Bodegas y vinos Grupo J. García Carrión

\begin{tabular}{|c|c|c|c|}
\hline Zonas vinícolas & Bodegas & Localización & Vinos \\
\hline DO La Rioja & Marqués de Carrión & Labastida & $\begin{array}{l}\text { Marqués de Carrión, Antaño, } \\
\text { Solar de Carrión, Montequinto }\end{array}$ \\
\hline DO Ribera del Duero & Viña Arnáiz & Haza & $\begin{array}{l}\text { Viña Arnáiz, Pata Negra Ribera } \\
\text { del Duero, Mayor de Castilla }\end{array}$ \\
\hline DO Cava & Jaume Serra & Vilanova i La Geltrú & Cavas Pata Negra y Jaume Serra \\
\hline DO Penedés & Jaume Serra & Vilanova i La Geltrú & Jaume Serra, Viña del Mar \\
\hline DO Cataluña & Jaume Serra & Vilanova i La Geltrú & Jaume Serra, Viña del Mar \\
\hline DO Valdepeñas & Los Llanos & Valdepeñas & $\begin{array}{l}\text { Señorío de los Llanos, Pata } \\
\text { Negra, Armonioso, Torneo y } \\
\text { Don Opa }\end{array}$ \\
\hline DO Rueda & Bodegas García Carrión-Rueda & Serrada & $\begin{array}{l}\text { Mayor de Castilla y Solar de la } \\
\text { Vega }\end{array}$ \\
\hline DO Jumilla & Bodegas 1890 & Jumilla & Castillo San Simón, Mayoral \\
\hline DO Toro & Bodegas Sietecerros & Villaester de Arriba- Pedrosa del Rey & Mayor de Castilla-Toro \\
\hline DO La Mancha & JGC-La Mancha & Daimiel & Don Luciano, Ópera Prima \\
\hline Vinos de la Tierra de Castilla & & Daimiel & Don Simón \\
\hline Otros vinos & & Daimiel & $\begin{array}{l}\text { Vino de mesa } \\
\text { Vinos bajos en alcohol } \\
\text { Vinos espumosos }\end{array}$ \\
\hline Otras bebidas & & Jumilla & Brandy 1890 \\
\hline Fuente: http://garciacarrion.es & es/inicio & & \\
\hline
\end{tabular}

Xérès-Sherry y Manzanilla de Sanlúcar de Barrameda, define cuatro tipos de establecimientos autorizados para operar en las distintas fases del proceso de producción de los vinos: 1) bodegas de elaboración, situadas en el área producción ${ }^{21}$, en las que se pisa la uva, se fermentan los mostos y se almacenan los vinos que posteriormente se dedicarán a la elaboración de productos protegidos; 2) bodegas de zona de producción, situadas en el área de producción y fuera de la zona de crianza, dedicadas al almacenado y envejecimiento de vinos aptos para ser criados posteriormente en las bodegas de crianza; 3 ) bodegas de crianza y almacenado, situadas en las correspondientes zonas de crianza ${ }^{22}$, dedicadas a la crianza y envejecimiento de vinos; y 4) las bodegas de crianza y expedición son las que, radicando en las correspondientes zonas de

${ }^{21}$ El área de producción de los vinos de ambas denominaciones de origen está formada por los municipios de Jerez de la Frontera, El Puerto de Santa María, Sanlúcar de Barrameda, Trebujena, Chipiona, Rota, Puerto Real, Chiclana de la Frontera y Lebrija.

${ }^{22}$ Los vinos protegidos por la Denominación de Origen Jerez-Xérès-Sherry deben criarse en bodegas enclavadas en los términos municipales de Jerez de la Frontera, El Puerto de Santa María o Sanlúcar de Barrameda: los de la Denominación de Origen Manzanilla-Sanlúcar de Barrameda únicamente en el término municipal de Sanlúcar de Barrameda. crianza se dedican a la crianza y venta para consumo de los vinos de las respectivas denominaciones ${ }^{23}$. La crianza más tradicional de esta zona es la dinámica, con mezclas de vinos con distintos niveles de vejez, conocida como de «criaderas y solera».

Muchas de las mayores empresas vinícolas tienen diversificada su producción en distintos tipos de vinos (de mesa, de la tierra, espumosos, con denominación de origen) y al mismo tiempo comercializan mostos y alcoholes. Además han acometido durante los últimos años un proceso de diversificación geográfica muy importante mediante la apertura de nuevas bodegas en ámbitos vitivinícolas distintos a aquellos de los que son originarias, sobre todo en los pertenecientes a las denominaciones de origen y a las indicaciones geográficas protegidas.

Anteriormente aludíamos a la existencia en el sector del vino de algunas grandes empresas. Las diez primeras, ordenadas por valor de las ventas, están relacionadas en el Cuadro VII. Encabezadas en 2013 por J. García

\footnotetext{
${ }^{23}$ Orden de 13 de mayo de 2010, por la que se aprueba el Reglamento de las Denominaciones de Origen Jerez-Xérès-Sherry y Manzanilla de Sanlúcar de Barrameda, así como sus correspondientes pliegos de condiciones. BOJA, $28 / 05 / 2010$.
} 


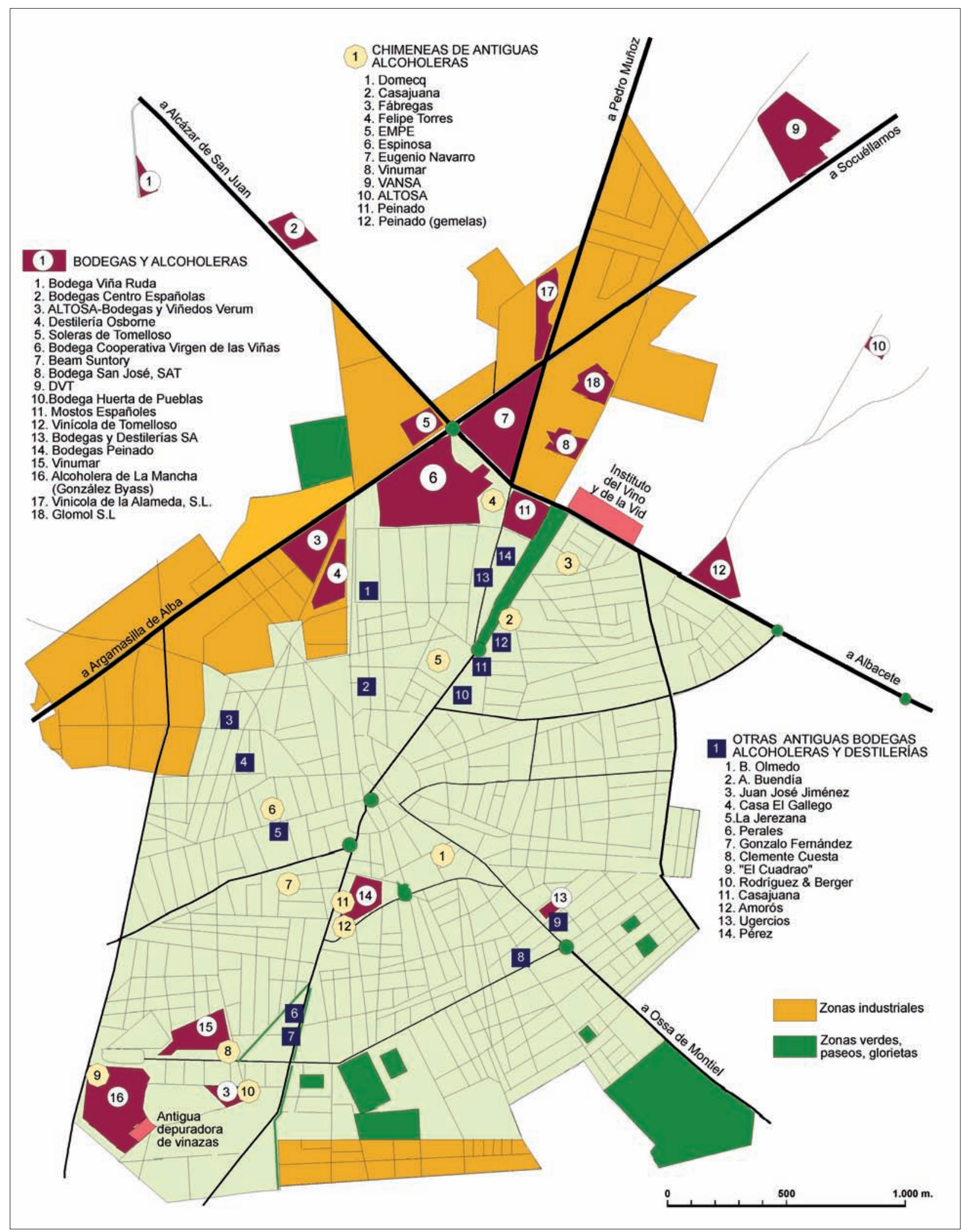

FIG. 13. Tomelloso, centro de producción de alcohol vínico y sede de la mayor cooperativa vinícola de Europa, la Cooperativa del Campo Vinícola Virgen de las Viñas. Fuente: elaborado a partir de Dirección General del Catastro (<http://www.catastro.meh.es>); Ayuntamiento de Tomelloso: «Historia de Tomelloso» (<http://www.tomelloso.es>); J. A. López Navarro: «Urbanismo Tomelloso» (<http://urbanismotomelloso.blogspot.com.es>). 
Cuadro IX. Vinos de la Cooperativa Virgen de las Viñas

\begin{tabular}{|c|c|c|}
\hline Mención & Marca & Tipo \\
\hline DO La Mancha & Don Eugenio Reserva & Tinto \\
\hline DO La Mancha & Monte Rodrigo Crianza & Tinto \\
\hline DO La Mancha & Monte Rodrigo & Tinto \\
\hline DO La Mancha & Tomillar Crianza & Tinto \\
\hline DO La Mancha & Tomillar & Tinto \\
\hline DO La Mancha & Fidencio & Tinto \\
\hline DO La Mancha & Tomillar $2 .^{\circ}$ año & Tinto \\
\hline DO La Mancha & Tomillar $3 .^{\circ}$ año & Tinto \\
\hline DO La Mancha & Tomillar & Rosado \\
\hline DO La Mancha & Tomillar $2 .^{\circ}$ año & Blanco \\
\hline DO La Mancha & Tomillar $3 .^{\circ}$ año & Blanco \\
\hline DO La Mancha & Lorenzete Airén & Blanco \\
\hline DO La Mancha & Rocío López López (Verdejo) & Blanco \\
\hline DO La Mancha & Tomillar Chardonnay & Blanco \\
\hline Vino de la Tierra de Castilla & Pasión Brava Merlot & Tinto \\
\hline \multirow[t]{4}{*}{ Vino de la Tierra de Castilla } & Tomillar & Tinto \\
\hline & Viña Tomilla & Tinto \\
\hline & Viña Tomilla & Blanco \\
\hline & Tomillar Sauvignon Blanc & Blanco \\
\hline
\end{tabular}

Carrión, concentran el $30 \%$ del empleo y el $47 \%$ de las ventas.

García Carrión, S. A., con origen en Jumilla, que además de liderar el mercado del vino es el primer fabricante de zumos (Don Simón), con una estructura muy diversificada desde el punto de vista de la producción y de la localización geográfica, ejemplifica el comportamiento de las grandes firmas vinícolas. Produce y comercializa vinos jóvenes, envejecidos, de mesa, de la tierra, con denominación de origen, espumosos...; utiliza uvas de diez denominaciones de origen, en la mayoría de ellas, si no en todas, procedentes de viñedos propios y, en algún caso, opera con fórmulas de acuerdos firmados con otros bodegueros (Cuadro VIII).

El sector cuenta también con importantes sociedades cooperativas, como la Cooperativa del Campo Vinícola Virgen de las Viñas, que por su facturación se ha situado en algunos ejercicios entre las diez mayores empresas vinícolas españolas. Fue creada en 1961 y en 2009 se fusionó con una almazara, también cooperativa ${ }^{24}$,

\footnotetext{
${ }^{24}$ En 2011 se fusiona también con la Cooperativa Vinícola San Gregorio, de Arenales de San Gregorio, por lo que en la actualidad cuenta con dos centros: uno
}

reuniendo un total de 2.500 socios. De ellos 2.000 son viticultores que agrupan 23.000 ha de viñedo y producen 200.000 toneladas de uva. La producción de vino y mosto asciende a unos 150 millones de litros, de los cuales el $90 \%$ corresponde a graneles, y su venta, realizada mayoritariamente en mercados comunitarios, aporta unos 70 millones de euros.

Como es propio de otras cooperativas, la de la Virgen de las Viñas circunscribe su ámbito de actividad a una única zona vinícola, la de vinos de La Mancha. Su producción, sin embargo, es muy variada y abarca procesos de embotellamiento y envejecimiento de vino (Cuadro IX), así como de elaboración y comercialización de vino ecológico (Ministerio de Agricultura, 2007).

La cooperativa, que es la mayor de Europa, tiene su sede en Tomelloso, donde convive con otras bodegas importantes y con destilerías y alcoholeras vinculadas a algunos de los nombres de mayor solera y tradición en el ámbito de las bebidas espirituosas. La ciudad manchega,

principal en Tomelloso, con secciones de bodega y almazara, y otro en Arenales de San Gregorio, con sección bodega. Incorporando sus socios a los ya existentes alcanzan en la actualidad los 3.000 socios en sus dos secciones productivas. 
principal núcleo agroindustrial de la provincia de Ciudad Real, conserva como elementos destacados de su patrimonio varias chimeneas de ladrillo, algunas de más de veinte metros de altura, pertenecientes a algunas de las cerca de 70 destilerías con las que llegó a contar en su momento de máxima apogeo, hacia 1950.

El auge de las alcoholeras estuvo impulsado por las deficientes comunicaciones de Tomelloso que entorpecían la salida de la abundante producción de vino, resultando más sencillo transportar y comercializar el volumen más reducido resultante de la destilación alcohólica. Las alcoholeras, inicialmente propiedad de vecinos de la localidad, pasaron más tarde a algunas de las más importantes empresas alcoholeras de nuestro país que convirtieron a Tomelloso en el primer productor mundial de alcohol vínico ${ }^{25}$ (Fig. 13).

Los edificios y otras instalaciones de las alcoholeras, construidos inicialmente en el interior del recinto urbano histórico, fueron trasladados de forma paulatina, a partir de mediados del siglo xx, a los nuevos espacios industriales diseñados en los bordes de la ciudad, sobre todo el septentrional. El proceso liberó numerosos solares cuya posterior ocupación permitió consolidar un espacio central de exclusiva función residencial y terciaria, cuyos únicos vestigios industriales son las chimeneas ${ }^{26}$ antes mencionadas.

\section{FUENTES Y BIBLIOGRAFÍA}

Ayuntamiento de Tomelloso, <www.tomelloso.es $>$.

Confederación Española de CoOperativas Agrarias de ESPAÑA (CCAE) (2004): Estudios sobre la comercialización. Sector Cooperativo. Elaborado por la CCAE para el Ministerio de Agricultura, Pesca y Alimentación, <http://www.magrama.gob.es/es/alimentacion/temas/ consumo-y-comercializacion-y-distribucion-alimentaria/estudios-de-comercializacion/sector-cooperativo>.

Comisión Europea: Agricultura y Desarrollo Rural. Base de datos E-Bacchus, <http://ec.europa.eu/agriculture/wine/e-bacchus/>.

CoOperativas Agroalimentarias (2011): Informe vitivinícola. Balance, <http://www.agro-alimentarias. coop/ficheros/doc/03506.pdf $>$.

- (2016): «Las cooperativas españolas en el sector del vino», ponencia de Gabriel Trenzado impartida en

\footnotetext{
25 «Historia de Tomelloso», en <http://www.tomelloso.es/>

${ }^{26}<$ http://urbanismotomelloso.blogspot.com.es/>.
}

Budapest el 29 de abril de 2016, <http://www.agroalimentarias .coop/ficheros/doc/04961.pdf>.

Dirección General del CATASTRo: Cartografía parcelaria, <http://www.catastro.meh.es>.

- Estadísticas catastrales, <http://www.catastro.meh.es>.

EuRostat: Encuesta de base a las superficies vitícolas, $<$ http://ec.europa.eu/eurostat/web/agriculture/data/ database $>$.

Fondo Español de Garantía Agraria (fega): Producción declarada de vinos y mostos. Distintos años

Granados AristizÁbal, J. I. (2012): «Las denominaciones de origen en la industria agrícola: una herramienta de distinción y competitividad». Producción + Limpia, vol. 7, núm. 2, pp. 95-105.

ICEX. EsPaña EXPORTACión E InVERSIONES (2014): El vino en cifras.

INE: Censo agrario 2009, <http://www.ine.es>.

Junta de Andalucía. Consejería De Agricultura y Pesca (2002): Diagnóstico del sector vitivinícola y de las bodegas en el Marco de Jerez. 83 pp.

LAngreo, A. (2006): «Análisis del sector vitivinícola español». Cuadernos de la Tierra, núm. 7, pp. 8-18.

Lissarrague, J. R., y F. Martínez de Toda (2009): Informe vitícola. Entidad Estatal de Seguros Agrarios (Enesa), <http://aplicaciones.magrama.es/documentos_pwe/seminarios/vinedo_upm_ur.pdf $>$.

Ministerio de Agricultura, Alimentación y Medio AmBIENTE (2012): Macromagnitudes agrarias. Cuentas regionales de la agricultura. <http://www.magrama. gob.es/es/estadistica/temas/estadisticas-agrarias/economia/cuentas-economicas-agricultura/ $>$.

- (2014a): Anuario de estadística, <http://www.magrama.gob.es/es/estadistica/temas/publicaciones/ anuario-de-estadistica $>$.

- (2014b): Datos de las Denominaciones de Origen Protegidas (DOPS) e Indicaciones Geográficas Protegidas (IGPS) de Productos Agroalimentarios, <http:// www.magrama.gob.es/es/alimentacion/temas/calidad-agroalimentaria/calidad-diferenciada/dop/htm/ cifrasydatos .aspx $>$.

- (2014c): Datos de las Denominaciones de Origen Protegidas de Vinos y de las Indicaciones Geográficas Protegidas de Vinos-Vinos de la Tierra, <http:// www.magrama.gob.es/es/alimentacion/temas/calidad-agroalimentaria/calidad-diferenciada/dop/htm/ cifrasydatos.aspx $>$.

- (2015a): Encuesta sobre Superficies y Rendimientos Cultivos (Esyrce), <http://www.magrama.gob.es/es/ estadistica/temas/estadisticas-grarias/agricultura/esyrce>. 
- (2015b): Potencial de producción vitícola en la unión europea y en España. Inventario de potencial vitícola a 31 de julio de 2014, <http://www.magrama.gob. es/es/agricultura/temas/regulacion-de-los-mercados/ informe-potencial-viticola-2015_tcm7-381565.pdf $>$.

- (2015c): Informe sobre la industria agroalimentaria. <http://www.magrama.gob.es/es/alimentacion/temas/industria-agroalimentaria/cifras-de-la-industriaalimentaria/>

Ministerio de Agricultura, Pesca y Alimentación (2003): Diagnóstico y Análisis Estratégico del Sector Agroalimentario Español. Análisis de la cadena de producción y distribución del sector del vino, $<\mathrm{http}: / /$ www.magrama.gob.es/es/alimentacion/temas/con- sumo-y-comercializacion-y-distribucion-alimentaria/ resumen_vino_tcm7-7968.pdf>.

- (2005): Estructura industrial del subsector de vinos. Diagnóstico y Análisis Estratégico del Sector Agroalimentario Español. Análisis de la cadena de producción y distribución del sector del vino, <http:// www.magrama.gob.es/es/alimentacion/temas/consumo-y-comercializacion-y-distribucion-alimentaria/ informe_vino_tcm7-7950.pdf>.

- (2007): Quién es quién en la agricultura ecológica. Directorio de empresas elaboradoras y comercializadoras de productos ecológicos, <http://www.magrama.gob.es/es/alimentacion/publicaciones/directorio_empresas_tcm7-8090.pdf $>$. 